\title{
Analysis of Three Situations of the Foehn Effect over the Andes (Zonda Wind) Using the Eta-CPTEC Regional Model
}

\author{
Marcelo E. Seluchi \\ Centro de Previsão de Tempo e Estudos Climáticos, Instituto Nacional de Pesquisas Espaciais, Cachoeira Paulista, Sao Paulo, Brazil \\ FEDERICO A. NORTE \\ Programa Regional de Meteorología, Instituto Argentino de Nivología, Glaciología y Ciencias Ambientales, and Centro Regional de \\ Investigaciones Científicas y Técnicas/CONICET, Mendoza, Argentina \\ PrakKi Satyamurty and Sin Chan Chou \\ Centro de Previsão de Tempo e Estudos Climáticos, Instituto Nacional de Pesquisas Espaciais, Cachoeira Paulista, Sao Paulo, Brazil
}

(Manuscript received 30 April 2001, in final form 25 October 2002)

\section{ABSTRACT}

\begin{abstract}
The zonda is a warm and extremely dry wind that occurs east of the Andes Cordillera in the extratropical latitudes of South America. Its orographic origin is similar to the foehn that blows in Germany and Austria and the chinook that occurs east of the Rocky Mountains. Three typical zonda events of different categories (surface and elevated) are described, through observational and Eta-Centro de Previsão de Tempo e Estudos Climáticos (CPTEC) model output. During the events the temperature rises sharply by $10^{\circ}-15^{\circ} \mathrm{C}$ and the dewpoint temperature drops by $15^{\circ}-20^{\circ} \mathrm{C}$ in an interval of a few hours. The sustained wind strength at the surface increases to $30 \mathrm{kt}$, with gusts of more than $40 \mathrm{kt}$. The episodes generally start around midday and last for about $10 \mathrm{~h}$.

The Eta-CPTEC model was able to forecast several aspects of the three analyzed zonda cases, such as wind strength, temperature, and humidity changes, and their starting and ending times. Some relationships between the intensity of the windward static stability and the zonda occurrence were observed. The synoptic pressure configuration resulting from frontal passages associated with depressions that moved over lower than normal latitudes preceded the zonda occurrence. Sensitivity experiments showed that if the Andes were lower, more frequent but less intense zonda episodes could be expected.
\end{abstract}

\section{Introduction}

Strong warm and very dry winds are occasionally observed descending from the mountains toward a valley or a plain. These winds have different names, depending on where they blow: "foehn" in central Europe (Germany, Austria, Switzerland) (Fleagle 1950; Klemp and Lilly 1975), "chinook" in Canada and the United States east of the Rocky Mountains (Brinkmann 1974; Zydek 2000), “canterbury-nor'wester" in New Zealand (Lamb 1974), "berg-wind" in South Africa (Lindesay 1990), and "zonda wind" in Argentina (Norte and Silva $1995)$ to the east of the Andes Cordillera near the Zonda Valley. [See Brinkmann (1971) for a definition of foehn effects around the world.] These winds generally exhibit the so-called foehn effect, which is produced when the air descends adiabatically from the lower middle tro-

Corresponding author address: Dr. Marcelo E. Seluchi, Centro de Previsao de Tempo e Estudos Climatocos CPTEC/INPE, Rod. Presidents Dutr Km 39., Cachoeira Paulista, SP 12630-000, Brazil.

E-mail: seluchi@cptec.inpc.br posphere to the foothills on the lee side of mountain ranges (Seibert 1990). Even though this process roughly describes the phenomenon, its spatial extension, intensity, frequency, and effects depend strongly on the topographic characteristics and the regional atmospheric circulation. Many authors have described the meteorological conditions associated with the occurrence of the foehn (Mannins and Sawford 1979; Wakonigg 1990; Egger and Hoinka 1992) and of the chinook (Lilly 1978; Oard 1993; Zydek 2000) in the Northern Hemisphere, in regions with good data coverage. The appearance of this effect in the Andes, however, has not been sufficiently documented and analyzed.

The Andes Cordillera runs meridionally from $55^{\circ} \mathrm{S}$ to $10^{\circ} \mathrm{N}$ with a mean width of $200-300 \mathrm{~km}$. The height varies with latitude. From the southernmost latitudes to $35^{\circ} \mathrm{S}$, the mean height does not exceed $2500 \mathrm{~m}$, which allows the westerly winds to pass over the mountains without much blocking. North of $35^{\circ} \mathrm{S}$, the cordillera rises rapidly, achieving a mean altitude of $4500 \mathrm{~m}$, with many peaks over $6000 \mathrm{~m}$, such as the Aconcagua Peak 


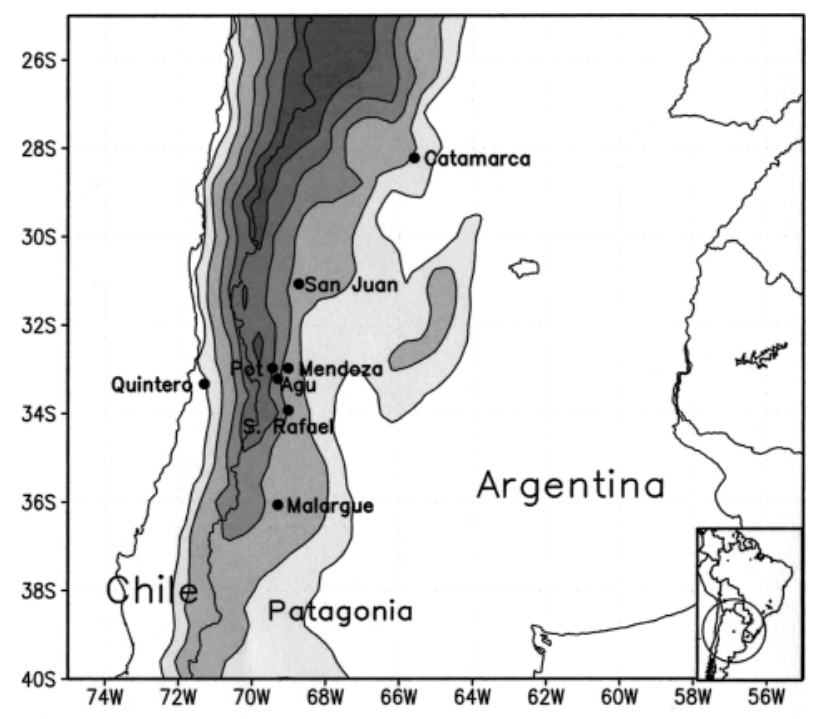

$\begin{array}{lllll}500 & 1000 & 2000 & 3000 & 4000\end{array}$

FIG. 1. Map of the region under study, including orography (m, elevations higher than $500 \mathrm{~m}$ are shaded) and location of the meteorological stations $(\mathrm{Agu}=$ Aguadtias and Pot $=$ Potrerillos $)$.

(6960 m). The foehn effect over these latitudes is less frequent, perhaps because the orographic obstacle becomes too high to be overcome by air masses coming from the west. On the windward side, a subsidence inversion, associated with the dry and stable subtropical anticyclone over the Pacific Ocean, lies above a shallow maritime air mass (Rutllant 1994; Garreaud 1999). In some situations, during the approach of an upper-level trough, the inversion weakens and is replaced by a frontal inversion that may rise to the middle levels near the mountaintop, where relatively strong winds predominate. Such a situation has been observed by Brinkmann (1974) to be a typical indicator of strong downslope windstorm conditions near the Rockies. An inversion near the mountaintop was also an ingredient in the simulations of mountain waves carried out by Durran (1986). The air on the lee slopes descends violently over the plains and the winds at the surface can exceed 50 $\mathrm{kt}$, causing damage to the foothill towns. In severe cases of the foehn effect near the Andes, often in winter and spring, the temperature may increase by as much as $20^{\circ} \mathrm{C}$ in a few hours or sometimes in minutes and the relative humidity may decrease to near $0 \%$ (Norte 1988). Although this phenomenon occurs on the entire length of the extratropical Andes, it is most frequently detected near the cities of Mendoza $\left[32^{\circ} \mathrm{S}, 69^{\circ} \mathrm{W}\right.$ and at $704 \mathrm{~m}$ above sea level (ASL)] and San Juan $\left(32^{\circ} \mathrm{S}, 68^{\circ} \mathrm{W}\right.$, and at $598 \mathrm{~m} \mathrm{ASL}$ ), which represent important urban regions of western Argentina (see Fig. 1).

Some characteristics of these singular and complex episodes were studied by Norte (1988) who carried out exhaustive descriptions of the typical climatic, synoptic, and thermodynamic conditions using data from aerological and surface stations for a 10-yr period (197483 ). In that work, two categories of zonda were distinguished: the "high" zonda and the "surface" zondas. The first type occurs when the wind reaches the stations located on the eastern slopes of the mountains but not the stations in the plains. The second is detected over the plains east of the Andes, typically in the proximity of the cities of Mendoza and San Juan. Norte (1988) found 220 high zonda episodes, among which only $6 \%$ reached the Mendoza airport. The events were considered light or moderate when the maximum winds were lower than $30 \mathrm{kt}$, severe when maximum gusts were equal to or greater than $30 \mathrm{kt}$ at Mendoza or San Juan, and very severe when the maximum winds were greater than $50 \mathrm{kt}$. The preferred starting time of the surface zonda wind was in the early afternoon hours, and severe cases started $2-3 \mathrm{~h}$ before midday and lasted until night hours.

A reliable and accurate forecast is necessary to relieve the acute discomfort that the zonda wind produces and the damages that it causes. The short spatial and temporal extension of the phenomenon, the sparse network of meteorological stations (especially mountain stations), and the presence of an orographic barrier with a great slope make this task difficult. Zonda forecasts are currently based on statistical techniques. Norte (1988) developed a method applying the stepwise discriminant analysis to the surface data that produces satisfactory results. The method was later extended by Norte and Seluchi (1993) using information from the thermodynamic profiles on both sides of the Andes. Nevertheless, these authors concluded that the processes occurring in the lower troposphere exhibit higher predictive value than those occurring at intermediate heights (see Norte and Silva 1995 for a revision). These statistical methods allow the prediction of the zonda occurrence up to 48 $\mathrm{h}$ in advance in terms of a yes-no table. The prediction of the zonda intensity or type (surface or high) is less reliable. The satellite imagery shows that moderate and severe zonda episodes are associated with midlevel clouds with a trapezoidal or triangular shape over central Chile and the adjacent Pacific Ocean (Norte et al. 1996). Although it is a subjective analysis, this cloud feature complements the mathematical-statistical forecasting methods.

Many aspects of the zonda wind still remain unexplored, particularly the three-dimensional structure of the phenomenon, which due to the scarcity of upper-air observations, has not been investigated in detail. The physical mechanisms related to the zonda and its different categories or variations have not been well documented in the literature. Moreover, there are no reports of numerical simulations or studies to assess the forecasting capability of regional models. The statistical and/or subjective forecasting methods used to date have shown low skill to determine the wind intensity or the starting and ending times of the zonda episodes. 
TABLE 1. Observation stations.

\begin{tabular}{lcc}
\hline \hline \multicolumn{1}{c}{ Station } & $\begin{array}{c}\text { Height ASL } \\
(\mathrm{m})\end{array}$ & Lat, lon \\
\hline San Juan & 598 & $32^{\circ} \mathrm{S}, 68^{\circ} \mathrm{W}$ \\
Mendoza & 704 & $33^{\circ} \mathrm{S}, 69^{\circ} \mathrm{W}$ \\
Potrerillos & 1300 & $33^{\circ} \mathrm{S}, 68^{\circ} \mathrm{W}$ \\
Aguaditas & 2230 & $33^{\circ} \mathrm{S}, 69^{\circ} \mathrm{W}$ \\
Quintero & 2 & $33^{\circ} \mathrm{S}, 70^{\circ} \mathrm{W}$ \\
San Rafael & 750 & $34^{\circ} \mathrm{S}, 69^{\circ} \mathrm{W}$ \\
Malargüe & 1425 & $36^{\circ} \mathrm{S}, 69^{\circ} \mathrm{W}$ \\
\hline
\end{tabular}

The present work undertakes a more complete description of three distinct zonda categories that represent three classical episodes: severe surface zonda, moderate surface zonda, and high zonda wind. The Eta-Centro de Previsão de Tempo e Estudos Climáticos (CPTEC) operational regional NWP model is evaluated as a potential forecasting tool and is employed to explore the three-dimensional structure of the phenomenon. The differences in the characteristics of the three categories are examined. Finally, the work attempts to explain the role of topography and to analyze some of the physical mechanisms associated with the zonda wind.

This work is structured as follows: section 2 describes the data and methodology used, section 3 presents a brief synoptic/mesoscale description of the three studied cases, while section 4 evaluates the forecast accuracy of the numerical model. Section 5 analyzes some physical processes involved in the occurrence of the zonda. Finally, the results obtained are summarized and discussed in section 6 .

\section{Data and methodology}

Three zonda episodes that occurred during August 1999 were selected based on observations from the stations listed in Table 1.

Mendonza and San Juan are the main cities of the region in which this work is focused. Mendoza, San Rafael, Malarguie, and San Juan are located at the foothills. Potrerillos and Aguaditas are located inside the "preAndes Cordillera" and records are only retrieved weekly, weather permitting. Comparisons between the Malargüe and San Juan stations can show the variations of zonda with latitude and/or the Andes blocking effect. Upper-air soundings are only provided at Quintero and Mendoza stations. The studied region is shown in Fig. 1.

The three chosen cases represent three different categories of the zonda phenomenon. The first event, which occurred on 5 August, was a severe episode that produced serious damage to the urban areas of Mendoza, causing disruption to the activities in the city. The intense gust winds removed roofs and uprooted trees and electricity posts. Its most prominent meteorological effect was a sudden rise in temperature followed by strong reduction of relative humidity. The event on 10 August exemplifies a typical episode of a relatively intense high zonda. The third case happened on 30 August and it was a classical case of a moderate surface zonda.

The synoptic situations were analyzed using the reanalysis data from the National Centers for Environmental Prediction-National Center for Atmospheric Research (NCEP-NCAR; Kalnay et al. 1996). These analyses are available every $6 \mathrm{~h}$ at $1.875^{\circ} \times 1.875^{\circ}$ latitudelongitude resolution and 17 vertical levels.

The regional Eta-CPTEC model was used for forecast evaluation and simulation experiments.

\section{Synoptic and mesoscale description}

\section{a. The severe zonda of 5 August 1999}

Figure 2 shows the synoptic situation on 1200 UTC 4 August 1999, from NCEP reanalyses. A surface depression centered near $50^{\circ} \mathrm{S}, 80^{\circ} \mathrm{W}$, west of the Andes, and a cyclonic appendage to the east of the Andes, across the continent, are observed at this time (Fig. 2a). The 500-1000-hPa thickness field (dashed lines) shows a baroclinic zone around $40^{\circ} \mathrm{S}$, associated with the wind maximum in the middle and upper troposphere (Fig. 2b). Northwest winds prevail in the upper troposphere and are associated with a long-wave trough, whose axis is meridionally along $90^{\circ} \mathrm{W}$. After $24 \mathrm{~h}$ (Fig. 3), the center of the surface depression has moved eastward and crossed the Andes. A frontal system is located north of Patagonia, which can be inferred from the cyclonic wind shear and the packing of 500-1000-hPa thickness lines. The low 1000-hPa geopotential heights to the east of the Andes are the result of the pressure fall that increased the zonal pressure gradient across the mountains, north of $35^{\circ} \mathrm{S}$. At $500 \mathrm{hPa}$, one can observe the intensification of the maximum wind region and its displacement to the north. The satellite image at 1800 UTC (Fig. 7) shows the cloudiness associated with the frontal system.

Figure 4 shows the hand-drawn surface analysis at 1800 UTC 5 August. Strong winds are evident along the southern Chilean coast and north of Patagonia, near $40^{\circ} \mathrm{S}$. These winds are commonly found during trough passages over this region. The intense pressure gradient across the Andes, north of $35^{\circ} \mathrm{S}$, is a consequence of the deep lee depression and the anticyclone over the Pacific Ocean. This cross-Andes pressure gradient is locally intensified by the mesoscale effect of mountain waves, which creates a negative pressure anomaly to the lee. The presence of the surface zonda north of the cold front can be identified by the high temperatures, above $30^{\circ} \mathrm{C}$, and the extremely low dewpoint temperatures. The observations at San Juan show an air temperature $(T)$ of $35^{\circ} \mathrm{C}$, a dewpoint temperature $\left(T_{d}\right)$ of $-55^{\circ} \mathrm{C}$, and dust produced by the turbulence. The value of $T_{d}=-55^{\circ} \mathrm{C}$ is physically "suspicious." However, the report originating from this standard synoptical station $3 \mathrm{~h}$ later, $T_{d}=-24.9^{\circ} \mathrm{C}$, corroborated the very low humidity values. The air and dewpoint temperatures re- 


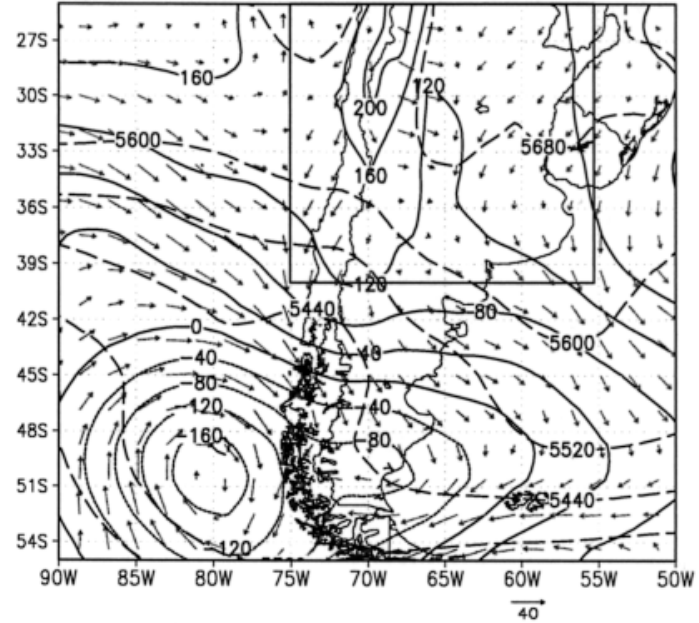

(a)

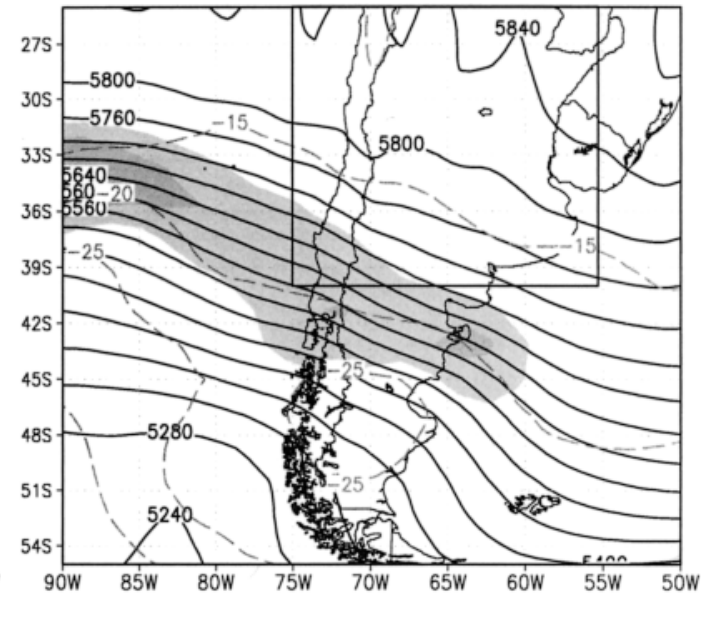

(b)

FIG. 2. Meteorological situation corresponding to 1200 UTC 4 Aug 1999 (NCEP analysis). (a) geopotential height of the 1000-hPa level (solid line, gpm), 500-1000-hPa thickness (dashed line, gpm), and winds at anemometer level (vectors; in kt). (b) The 500-hPa geopotential height (solid line, gpm), temperature (dashed line, ${ }^{\circ} \mathrm{C}$ ), and winds (light shading 80-120-kt interval, darker shading $>120 \mathrm{kt}$ ). Solid rectangle corresponds to the region shown in Fig. 1.

corded at $1500 \mathrm{UTC}$ were $27^{\circ}$ and $-1{ }^{\circ} \mathrm{C}$, respectively, and were $21^{\circ}$ and $3^{\circ} \mathrm{C}$ at the same hour on the previous day. The large contrast in temperatures between stations situated at the same latitude on the two sides of the Andes is also worth noting. Nevertheless, the contrast in the equivalent potential temperature across the mountains is only $4 \mathrm{~K}$ at the $925-\mathrm{hPa}$ level. An important aspect is that, because this is a mesoscale phenomenon, the characteristics found in the hand-drawn analysis (Fig. 4) are less clear and intense in the NCEP reanalysis due to its relatively low resolution.

Figure 5 depicts the air and dewpoint temperatures, relative humidity, and wind at Mendoza, Aguaditas, and Malarguie. The zonda wind was initially detected at the Aguaditas station, which is located at $2200 \mathrm{~m} \mathrm{ASL}$, at around 1600 UTC 4 August through a moderate humidity decrease and a slight temperature rise. This signal lasted until 0600 UTC 5 August. Norte (1988) found that changes in the relative humidity are usually more important than those in the temperature at mountain sites. Northwesterlies and westerlies at Aguaditas (Fig. 5d) gradually increased in intensity during this period, reaching $30 \mathrm{kt}$ on 5 August. The backing of the wind with time reveals the trough passage. The temperature decrease and the humidity rise prior to the maximum westerly winds are presumably related to the progressive cloud coverage. On the plains of Mendoza (Fig. 5a), the zonda symptoms were detected after 1200 UTC on 5 August and its effect was clearly apparent by 1500 UTC with an abrupt temperature increase and a dewpoint tem-

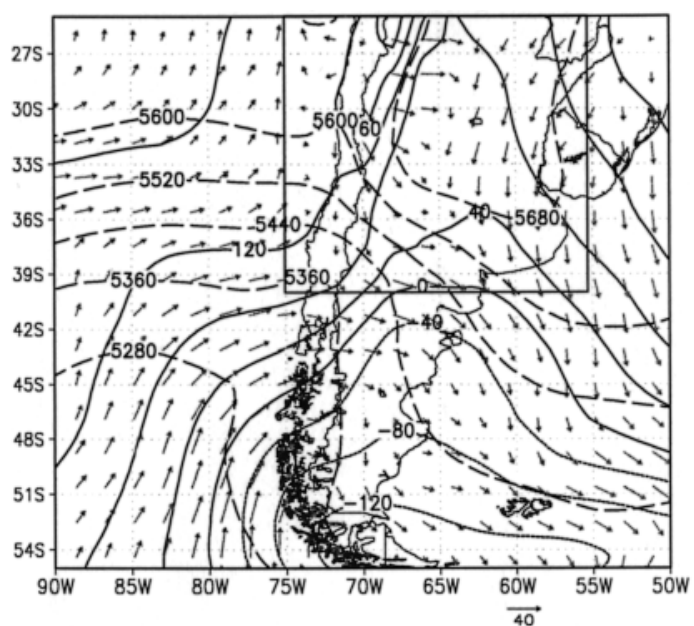

(a)

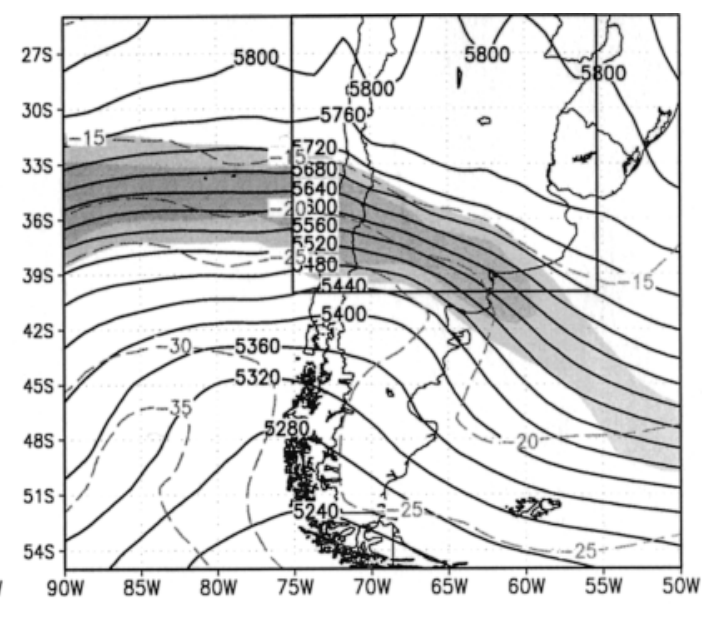

(b)

FIG. 3. Same as in Fig. 2 except at 1200 UTC 5 Aug 1999. 


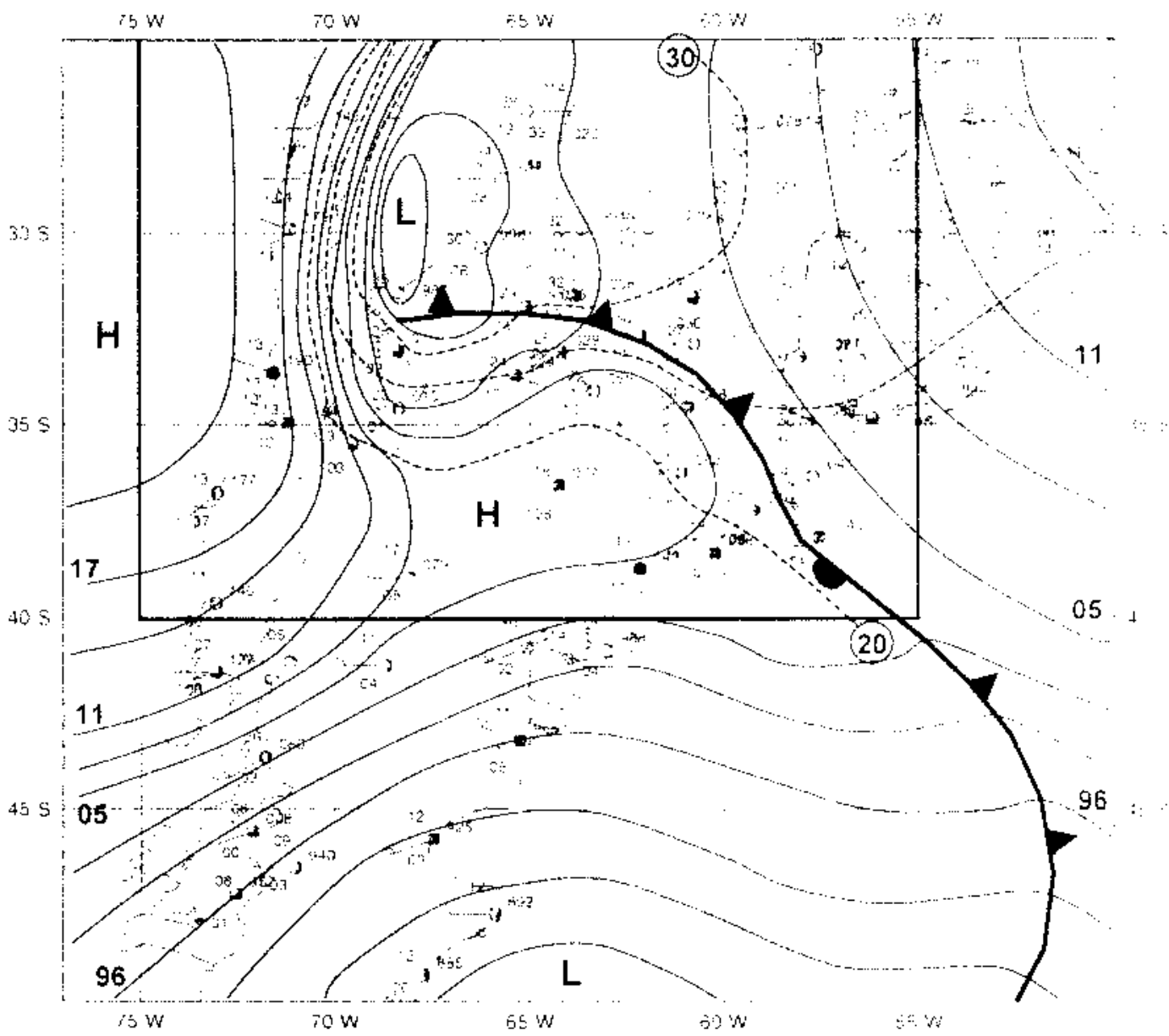

FIG. 4. Hand-drawn analysis corresponding to 1800 UTC 5 Aug 1999. Isobars (solid lines) at 3-hPa intervals and isotherms (dashed lines) at $5^{\circ} \mathrm{C}$ intervals. Symbols used have their usual meaning. Wind barbs are in kt. Solid rectangle corresponds to the region shown in Fig. 1.

perature fall. The zonda attained its maximum intensity near 1800 UTC 5 August, when the dewpoint depression reached $40^{\circ} \mathrm{C}$ and southwesterly winds of $30 \mathrm{kt}$ were observed.

Since Malargüe station is situated farther south in a region where the cordillera is considerably lower, the zonda winds start earlier (as in Fig. 5e) than those detected north of $34^{\circ} \mathrm{S}$. They have the same temperature and humidity signature as those detected at Mendoza or San Juan but they are usually more frequently observed and linked to a wider variety of synoptic patterns involving cold fronts.

Figure 6 shows the soundings taken at 1200 UTC 5 August, at Quintero and Mendoza stations. At the upstream station, Quintero, the air profile is cold and humid, especially above $700 \mathrm{hPa}$ where the typical strong inversion appears as a rather humid isothermal layer. The air column is close to saturation up to $500 \mathrm{hPa}$, agreeing with the appearance of rain over the Chilean coast (see Fig. 4). In contrast, the sounding at Mendoza is much warmer and drier at all levels, particularly at lower levels. The lapse rate on the eastern slopes is close to the dry adiabatic, and the progressive increase of the relative humidity with height, indicated by dewpoint depression decrease, suggests subsidence reaching near the surface. The observed wind profile at Mendoza shows speeds of $30 \mathrm{kt}$ at levels as low as $700 \mathrm{~m}$ above the station, which is at the foothills of the Andes. Brinkmann (1974) also reported similar characteristics for the downslope windstorms near Boulder, Colorado. The satellite image at 1800 UTC (Fig. 7) shows that the cloudiness is abruptly interrupted immediately east of the Andes as a consequence of the drying produced by adiabatic descent of air.

The zonda wind over the cities of Mendoza and San Juan ceased around 0000 UTC 6 August after the passage of the frontal system, leading to a sudden drop of temperature by almost $20^{\circ} \mathrm{C}$ in $12 \mathrm{~h}$ (Fig. 5a).

\section{b. The high zonda of 10 August 1999}

Figure 8 shows the surface and upper-level maps corresponding to 1200 UTC 10 August 1999 taken from NCEP-NCAR reanalysis. The synoptic pattern is sim- 
(a)
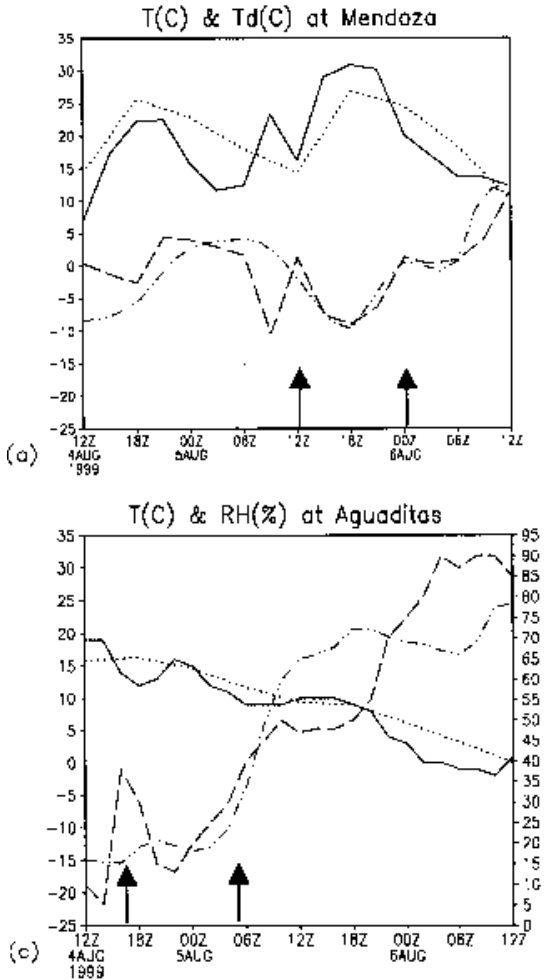

$T(C)$ \& $T(C)$ at Molorgue

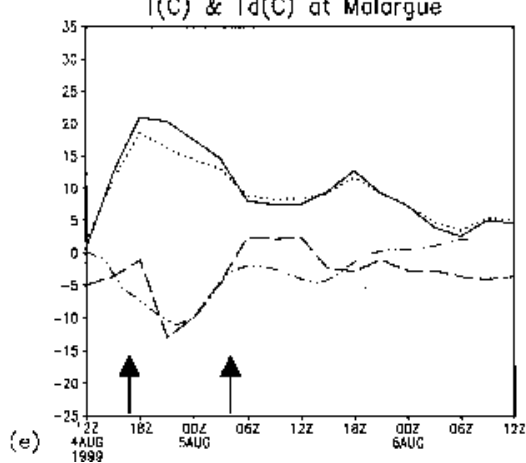

Wind (kt) of Mendoza
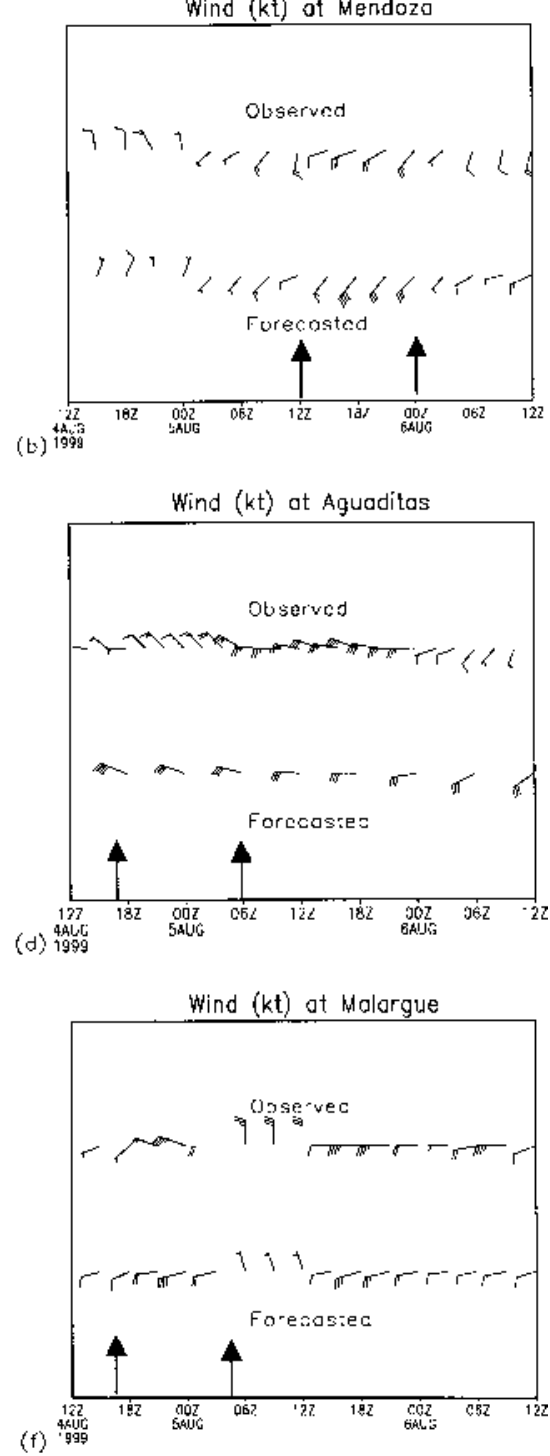

FIG. 5. Temporal evolution of observed and forecast (Eta-CPTEC model) meteorological variables at the indicated stations (see geographic location in Fig. 1). (a), (e) Observed temperature $\left({ }^{\circ} \mathrm{C}\right.$, solid lines), observed dewpoint temperature $\left({ }^{\circ} \mathrm{C}\right.$, dashed lines), forecast temperature $\left({ }^{\circ} \mathrm{C}\right.$, dotted lines), and forecasted dew point temperature $\left({ }^{\circ} \mathrm{C}\right.$, dot-dot-dash lines). (c) Observed temperature $\left({ }^{\circ} \mathrm{C}\right.$, solid lines), observed relative humidity (\%, dashed lines), forecast temperature $\left({ }^{\circ} \mathrm{C}\right.$, dotted lines), and forecasted relative humidity (\%, dot-dot-dash lines). (b), (d), (f) Observed winds (kt) and forecasted winds (kt). Arrows in (a)-(c) indicate zonda starting and terminating times, respectively.

ilar to the case of 5 August (Fig. 3). A depression is to the lee of the Andes over the Atlantic Ocean and a trough extends meridionally up to subtropical latitudes. However, there are some important differences such as the eastward location of the surface cyclone, a stronger baroclinicity near $40^{\circ} \mathrm{S}$ and a more zonal direction and a greater intensity of the flow at the middle and upper levels. The surface synoptic observations at 1800 UTC 10 August (Fig. 9) reveal that over the Malargüe station there were strong surface winds (about $30 \mathrm{kt}$ ) and a large dewpoint depression. However there is no evi- dence of the phenomenon at the foothill stations of Mendoza and San Juan. Moreover, Figs. 10a and 10b show small diurnal variations in the dewpoint temperature and light winds indicating that zonda wind was not blowing at Mendoza. However, the zonda signature is present at the Potrerillos station, on the Andean slopes (Figs. 10c and 10d), since after 0600 UTC, the temperature rises, humidity falls, and westerly winds become stronger. This zonda lasted until 1800 UTC 10 August. A difference with respect to the 5 August event is that the vertical profile of Quintero (not included) was much 

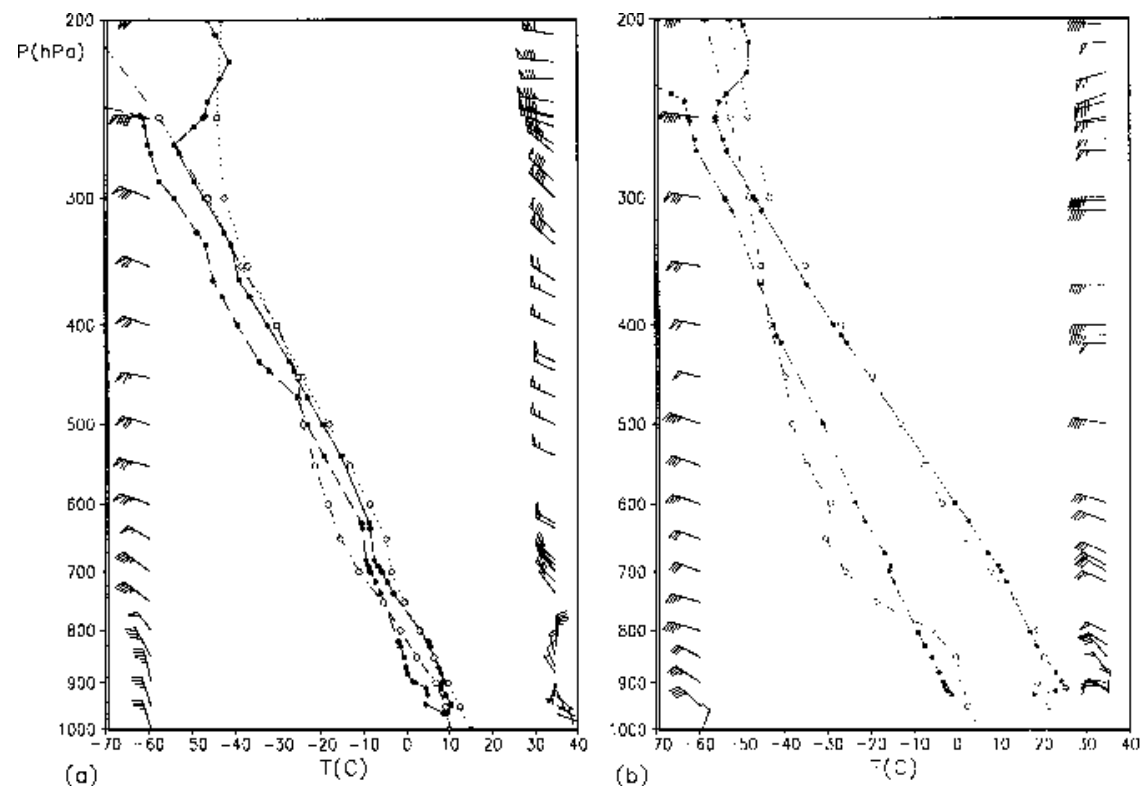

FIG. 6. Aerological soundings at 1200 UTC on 5 Aug 1999 at (a) Quintero and (b) Mendoza stations. The profiles correspond to the observed temperature $\left({ }^{\circ} \mathrm{C}\right.$, solid line) and dewpoint temperature $\left({ }^{\circ} \mathrm{C}\right.$, dashed line), and those forecast by the Eta-CPTEC model at the nearest grid point (temperature in dotted lines and dewpoint temperature in dot-dot-dash lines). Observed (forecasted) wind profile is shown on the right (left) side. Winds are in kt.

drier than the profile shown in Fig. 6. On the other hand, upstream flow at the middle troposphere was considerably stronger in comparison to Fig. 6a. In general, very strong wind above the mountaintop can interfere with the low-level amplification of mountain waves by suppressing wave breaking aloft (Durran 1990).

\section{c. The surface zonda of 30 August 1999}

The event on 30 August 1999 was a surface zonda of moderate intensity over Mendoza and San Juan. It

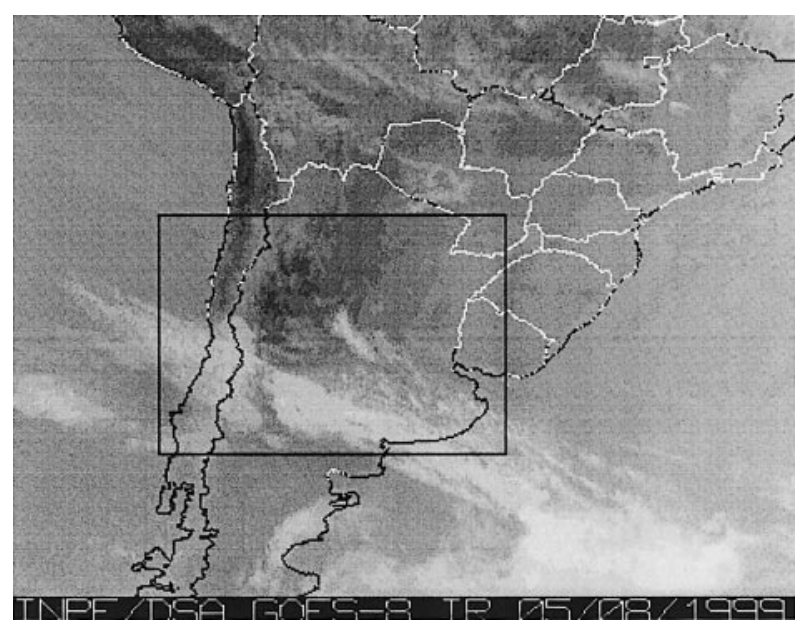

FIG. 7. GOES infrared satellite image corresponding to 1800 UTC 5 Aug 1999. Dark rectangle corresponds to the region shown in Fig. 1. was significantly different from the previous cases. The days prior to the zonda occurrence were characterized by the slow approach of an intense cyclone of an equivalent barotropic structure in the middle latitudes. There was an anticyclone east of $60^{\circ} \mathrm{W}$; over northwestern $\mathrm{Ar}$ gentina, a depression was developing. On 30 August, the depression was located over the continent in the northern portion of a baroclinic region (Fig. 11). The jet stream was, in this case, displaced to the north with respect to the previous two situations (cf. Figs. 11, 8, and $3 \mathrm{~b}$ ). The hand-drawn analysis at 1800 UTC $30 \mathrm{Au}-$ gust (Fig. 12) shows the zonal pressure gradient typical of zonda cases (Norte 1988). The zonda signs were clear over San Juan where air and dewpoint temperatures were $27^{\circ}$ and $-18^{\circ} \mathrm{C}$, respectively, with westerly winds of $30 \mathrm{kt}$. However, the temperature, the dewpoint depression, and the winds in Mendoza indicate that this case was weaker than the event of 5 August (Figs. 13a and 13b). A moderate zonda was also evident at San Rafael station, located south of Mendoza and at a lower altitude than Potrerillos, where temperature rise is accompanied by humidity fall. The zonda signature over the southern station of Malargüe is weaker than in the case of 5 August, but it could still be detected, for example at 1800 UTC, when air and dewpoint temperatures were $13^{\circ}$ and $-6^{\circ} \mathrm{C}$, respectively, and the westerly winds were $25 \mathrm{kt}$. One significant difference between this event and the other two cases was that the affected stations were not located north of a cold front, as seen in Fig. 12. On the following days, these stations were 


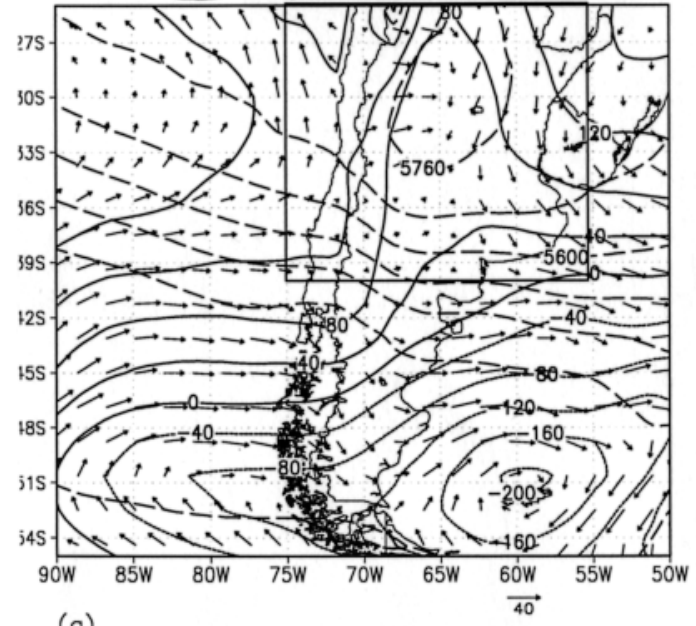

(a)

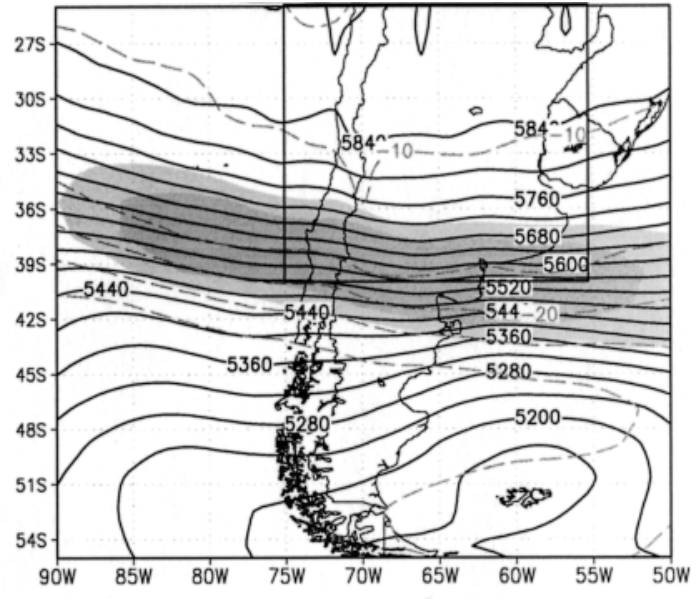

(b)

FIG. 8. Same as in Fig. 2 except for 1200 UTC 10 Aug 1999.

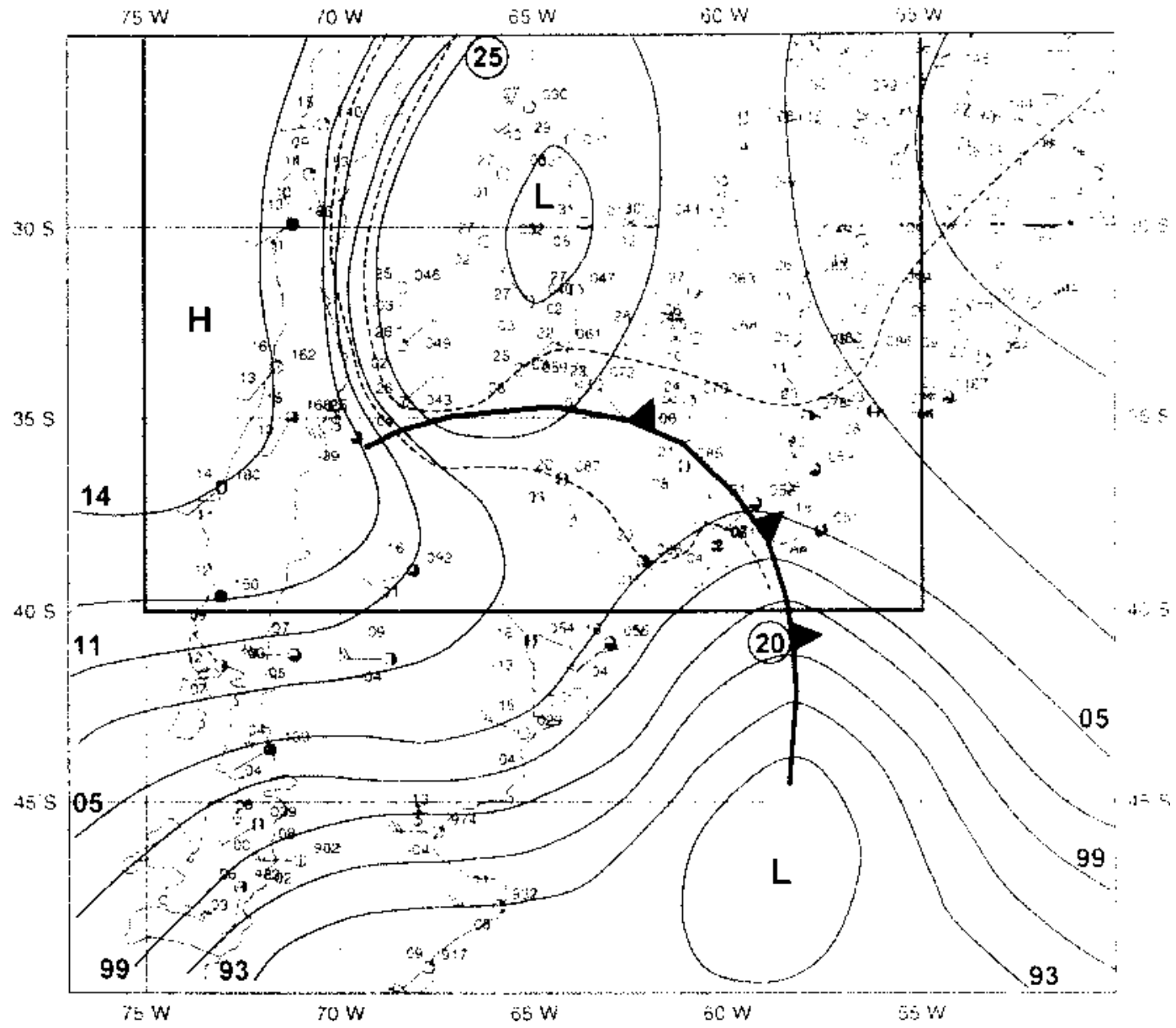

FIG. 9. Same as in Fig. 4 except for 1800 UTC 10 Aug 1999. 
$\mathrm{T}(\mathrm{C}) \& \mathrm{Td}(\mathrm{C})$ ot Mendozo

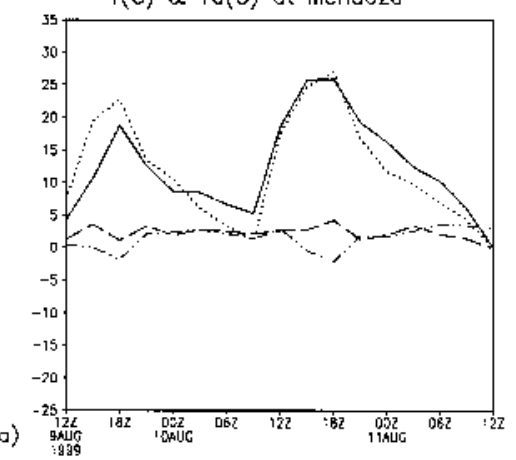

$\mathrm{T}(\mathrm{C})$ \& $\mathrm{RH}(\%)$ at Potrerillos

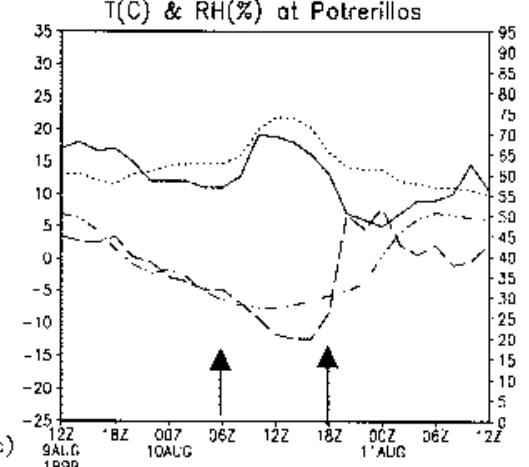

$T(C) \& \operatorname{Td}(C)$ ot Molarglue

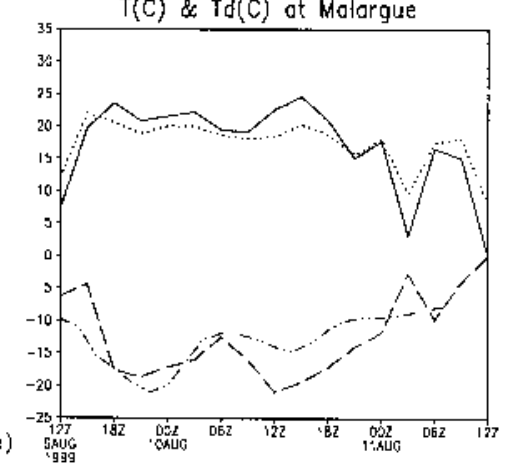

(b) 199
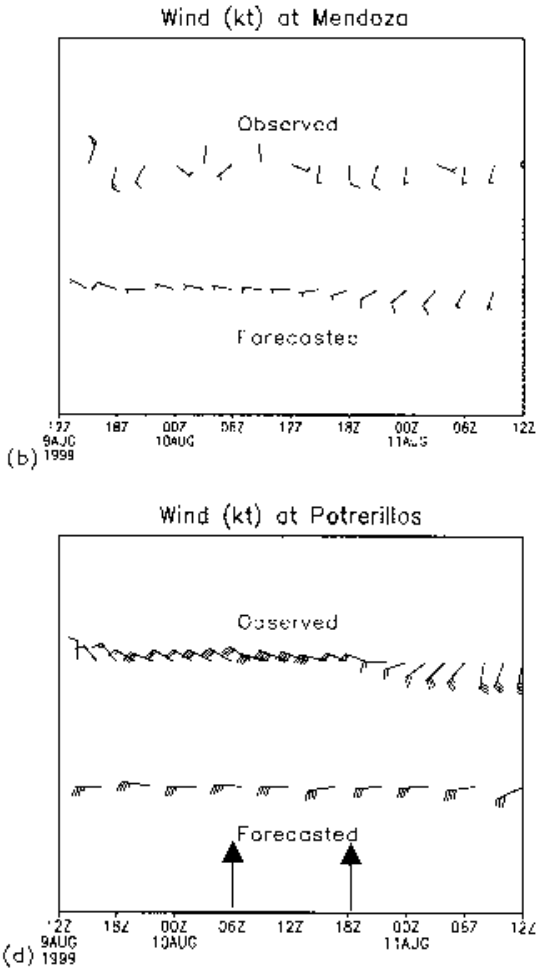

Wind (kt) at wolorgue

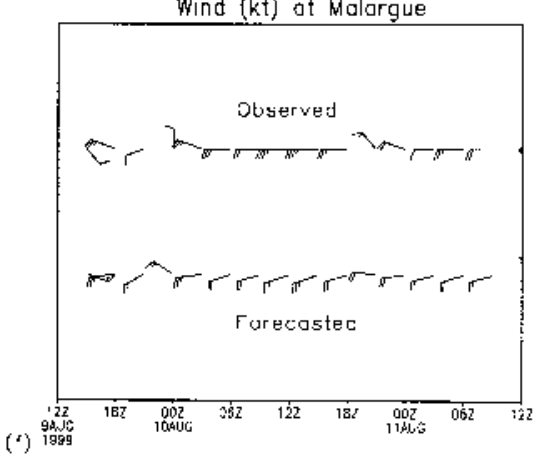

FIG. 10. Same as in Fig. 5 except for 10 Aug 1999.

again affected by the phenomenon, until the passage of a moderate frontal system, which changed the pressure configuration on the first days of September 1999.

Table 2 summarizes some of the characteristics of the zonda wind cases of August 1999.

\section{Forecast evaluation}

In this section, the ability of the Eta-CPTEC model to forecast the zonda episodes is assessed. It is mainly intended to determine the potential of the model to capture synoptic aspects related to orographic winds and the associated local-scale conditions on the eastern slopes of the Andes.

For the three cases described in section 3, the model integrations began at 0000 UTC on the day before the occurrence of the zonda wind, which is $36-48 \mathrm{~h}$ before its eruption, in order to forecast the beginning and the end of the phenomenon. The initial condition was taken from the NCEP analysis and the lateral boundaries are provided at 6-h intervals by the operational CPTECCenter for Ocean-Land-Atmosphere (COLA) global model at 62 zonal wave triangular truncation and 28 levels (T62L28).

The Eta-CPTEC model is hydrostatic and uses the eta vertical coordinate defined by Mesinger (1984). The model is integrated with horizontal resolution of $40 \mathrm{~km}$ and 38 vertical levels over the South American continent and the adjacent oceans from $50^{\circ} \mathrm{S}$ to $12^{\circ} \mathrm{N}$ and from $83^{\circ}$ to $26^{\circ} \mathrm{W}$. The time step used is $96 \mathrm{~s}$. The model possesses a comprehensive physics package including large-scale and convective precipitation (Betts and Mill- 


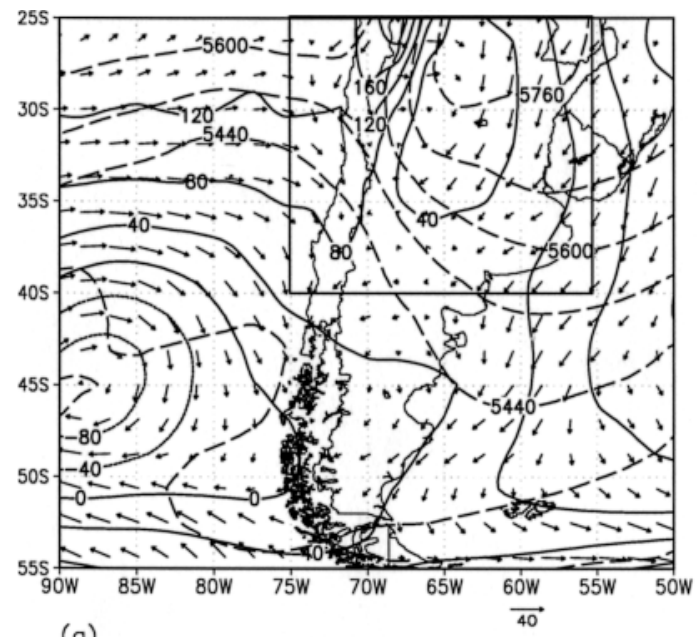

(a)

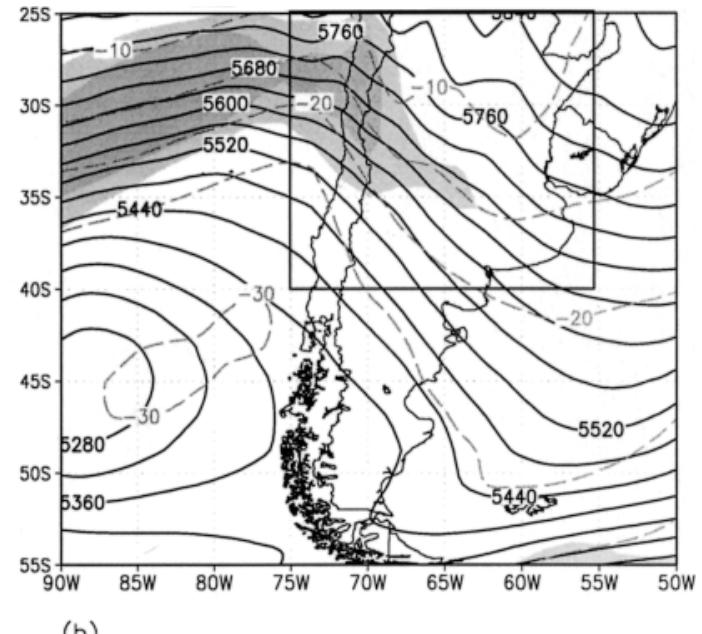

(b)

FIG. 11. Same as in Fig. 2 except for 1200 UTC 30 Aug 1999.

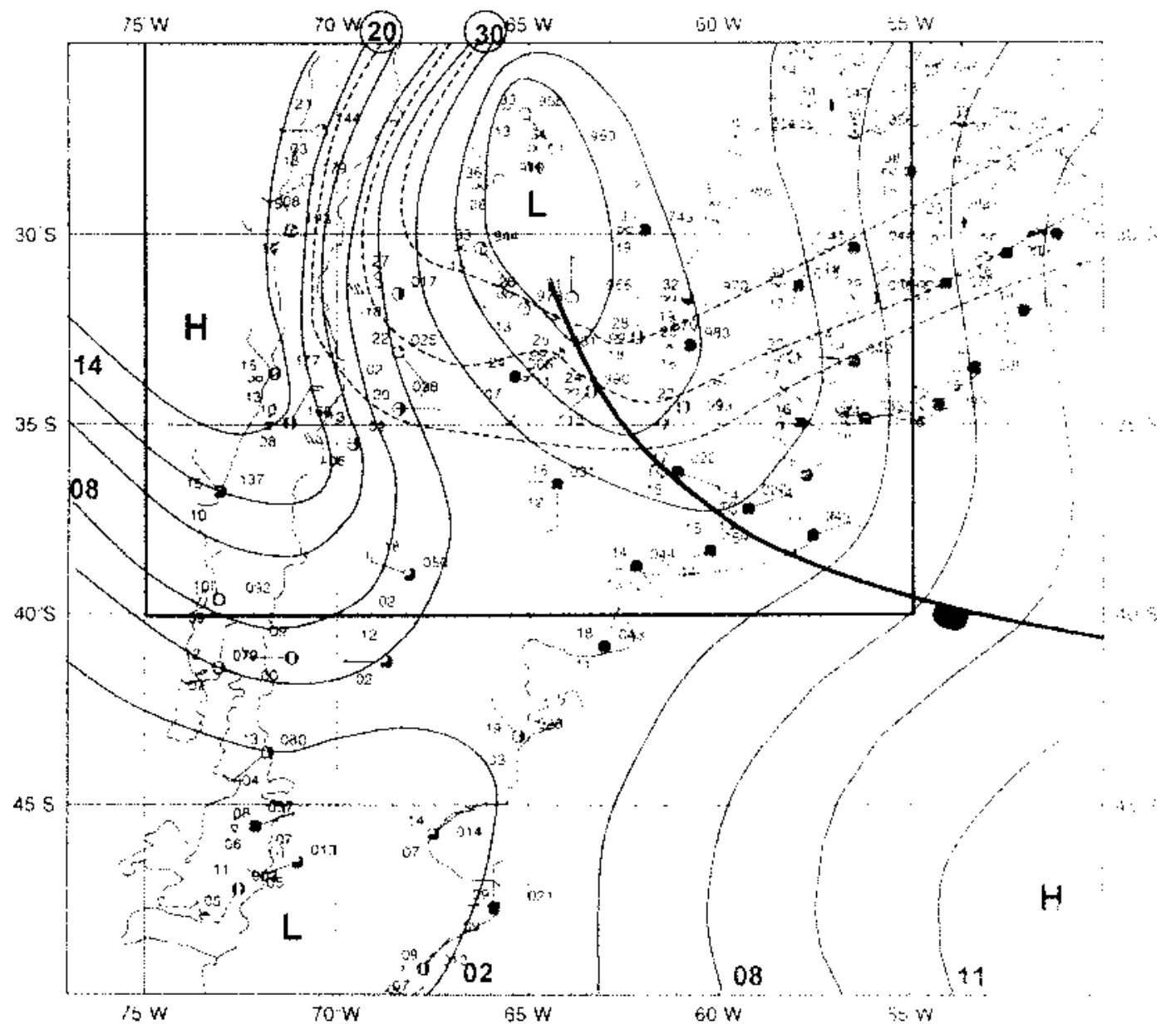

FIg. 12. Same as in Fig. 4 except for 1800 UTC 30 Aug 1999. 


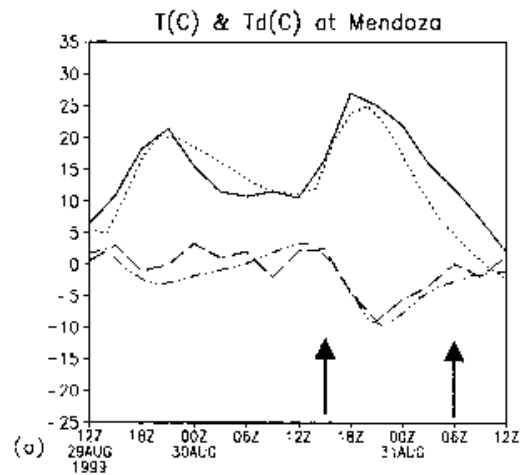

$T(C)$ \& $T(C)$ ot Son Rafoe:

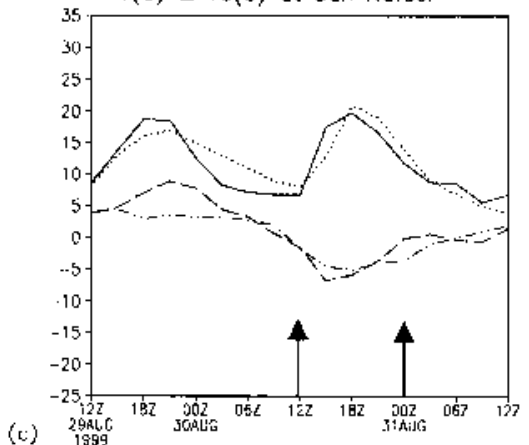

$T(C) \&$ Td(C) ot Malergus

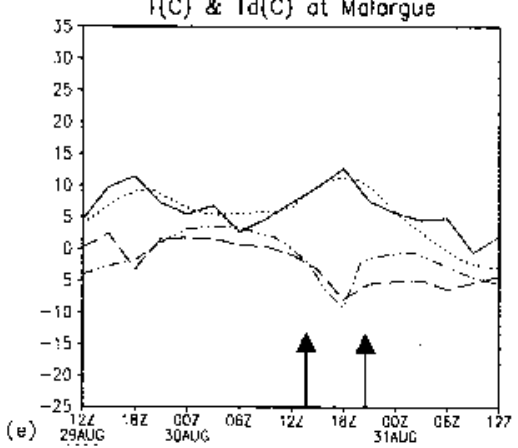

unind (kt) at kendozo
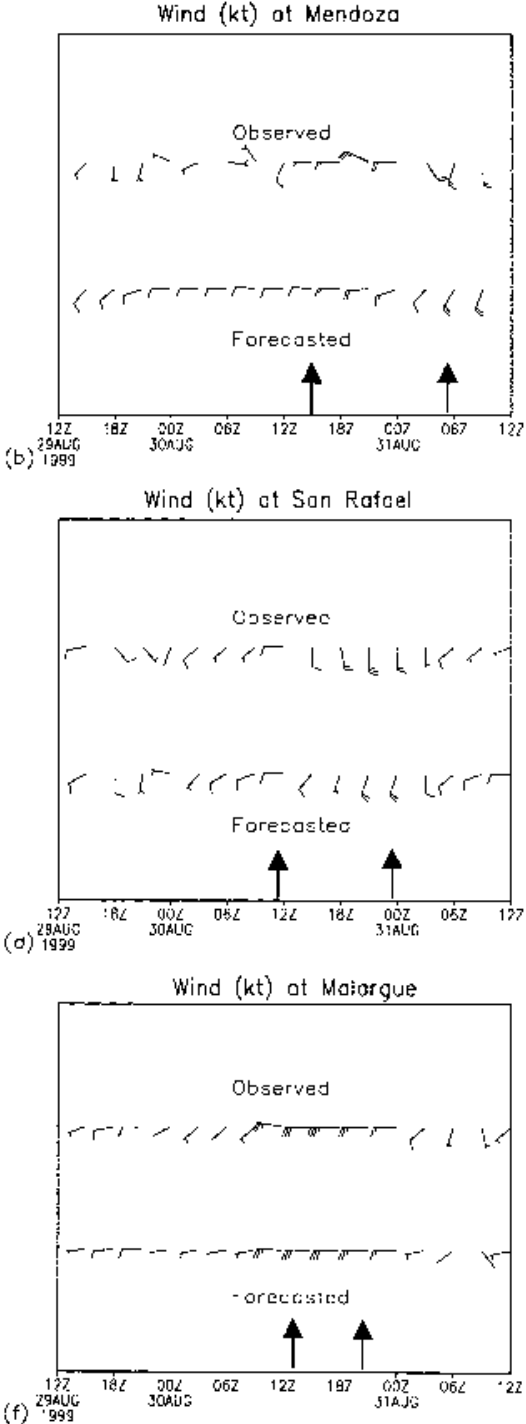

FIG. 13. As in Fig. 5 except for 30 Aug 1999.

er 1986; Janjić 1994), turbulent exchanges, surface processes (Chen and Avissar 1994), and radiative transfer representations. More details may be found in Black (1994).

Panels a and b in Figs. 14, 15, and 16 show the mean sea level pressure, $10-\mathrm{m}$ winds, cloud cover fraction, and 500-hPa geopotential height forecasts valid for 1800
UTC, when a zonda wind was blowing in the three selected situations. Agreement between the forecasts and the observations or analyses can be seen by comparing the sea level pressure (Figs. 9, and 12, and corresponding Figs. 14a, 15a, and 16a) of the surface regional conditions. The ability to reproduce the zonal pressure gradient across and on the lee side of the Andes,

TABLE 2. Some characteristics of three zonda wind cases during Aug 1999.

\begin{tabular}{|c|c|c|c|c|}
\hline Case & Starting time and place & Ending time & Area & Max wind speed \\
\hline 5 Aug & $\begin{array}{l}1600 \text { UTC, } 4 \text { Aug at Aguaditas } \\
1200 \text { UTC, } 5 \text { Aug at Mendoza }\end{array}$ & $\begin{array}{l}0600 \text { UTC, } 5 \text { Aug at Aguaditas } \\
0000 \text { UTC, } 6 \text { Aug at Mendoza }\end{array}$ & $\begin{array}{l}\text { From Malargüe to } \\
\text { San Juan }\end{array}$ & $\begin{array}{l}30 \mathrm{kt} \text {, at Aguaditas; } \\
30 \mathrm{kt} \text {, at Mendoza }\end{array}$ \\
\hline 10 Aug & $\begin{array}{l}0600 \text { UTC, } 10 \text { Aug at Potrerillos } \\
\text { and Aguaditas }\end{array}$ & $\begin{array}{l}1800 \text { UTC, } 10 \text { Aug at Potrerillos } \\
\text { and Aguaditas }\end{array}$ & $\begin{array}{l}\text { Andean slopes from } \\
\text { San Rafael to Po- } \\
\text { trerillos }\end{array}$ & $44 \mathrm{kt}$, at Potrerillos \\
\hline 30 Aug & 1200 UTC, 30 Aug at San Rafael & 0600 UTC, 31 Aug at Mendoza & $\begin{array}{l}\text { From Malargüe to } \\
\text { Catamarca }\end{array}$ & $\begin{array}{l}30 \mathrm{kt} \text {, at Malargüe; } \\
25 \mathrm{kt} \text {, at Mendoza }\end{array}$ \\
\hline
\end{tabular}




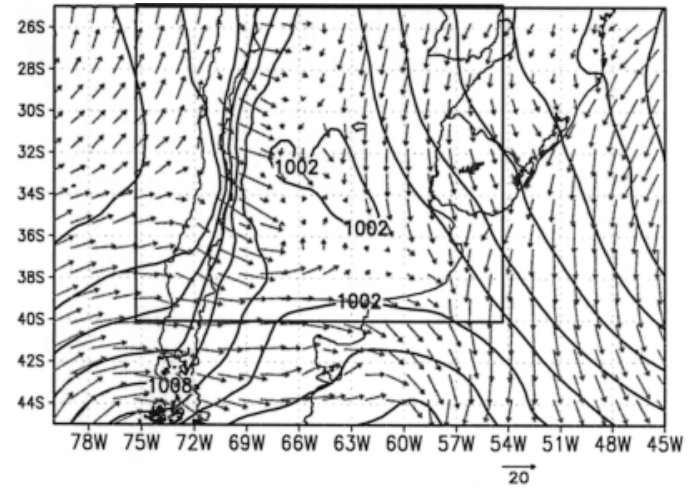

(a)

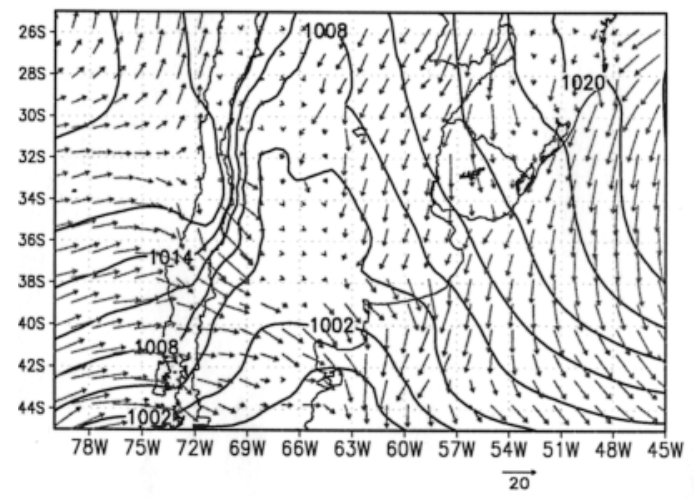

(c)

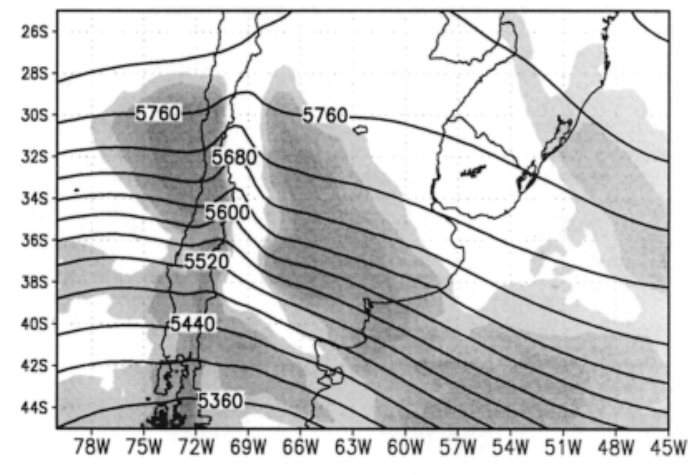

(b)

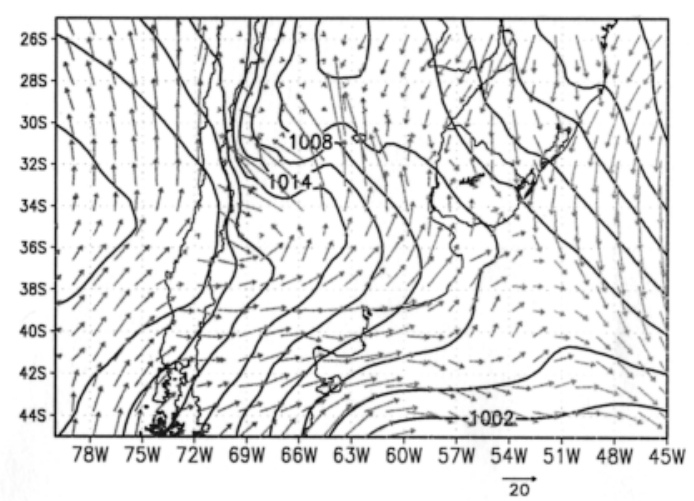

(d)

FIG. 14. The 42-h forecast valid for 1800 UTC 5 Aug 1999: (a) sea level pressure (solid lines, every 3 hPa) and wind at anemometer level (vectors, kt), (b) geopotential height at 500-hPa level (solid line, every $40 \mathrm{gpm}$ ) and cloudiness (\%, shaded according to grayscale shown), (c) same as in (a) except for 36-h forecast valid for 1200 UTC 5 Aug 1999, and (d) same as in (a) except for 60-h forecast valid for 1200 UTC 6 Aug 1999.

although with less intensity than observations, and to distinguish the differences among the three cases provides some confidence in the model.

On 5 August (Fig. 14) intense surface winds north of $40^{\circ} \mathrm{S}$ in the lee of the mountains were indicated by the model forecasts. The location of the 500-hPa trough and the abrupt interruption of the cloudiness (see Fig. 14b) immediately to the lee of the Andes were well captured. In the case of 10 August, strong surface winds were predicted near Malargüe (Fig. 15), which is in good agreement with the observations. The interruption of the cloudiness and the existence of westerly winds in the middle troposphere were also satisfactorily predicted. The episode of 30 August (Fig. 16) was also well captured by the forecast, especially the locations of the zonda winds that were stronger north of $32^{\circ} \mathrm{S}$.

The Eta-CPTEC model was able to indicate not only the occurrence of the zonda wind but also the approximate beginning and termination times. In all cases, the model predicted, during the hours prior to the zonda, relatively intense westerly winds in the region of Ma- largüe, around $36^{\circ} \mathrm{S}$, but not over Mendoza or San Juan to the north (Figs. 14c and 16c). The ending times of these episodes, 12-18 $\mathrm{h}$ after their beginning, was also captured (Figs. 14d and 16d).

The 36-h forecast of $T$ and $T_{d}$ profiles for Quintero and Mendoza valid for 1200 UTC on 5 August along with the corresponding observations $6 \mathrm{~h}$ prior to the maximum intensity of the zonda can be compared in Fig. 6. Even though the zonda wind was not blowing close to the surface at that time, its effect was clearly noticed in the layers above. It can be said that the model captured the essential thermodynamic characteristics such as the humidity contrast on both sides of the Andes. Inversions are present in the model, but with smaller magnitude, particularly the surface and tropopause. The temperature difference between the 800- and 400-hPa levels, which is indicative of the lower middle-troposphere stability conditions, is $48^{\circ} \mathrm{C}$ in both observation and in the forecast at Mendoza. The dry conditions near the 700-hPa level are exaggerated by the model. The error in tropopause location is a systematic problem of 

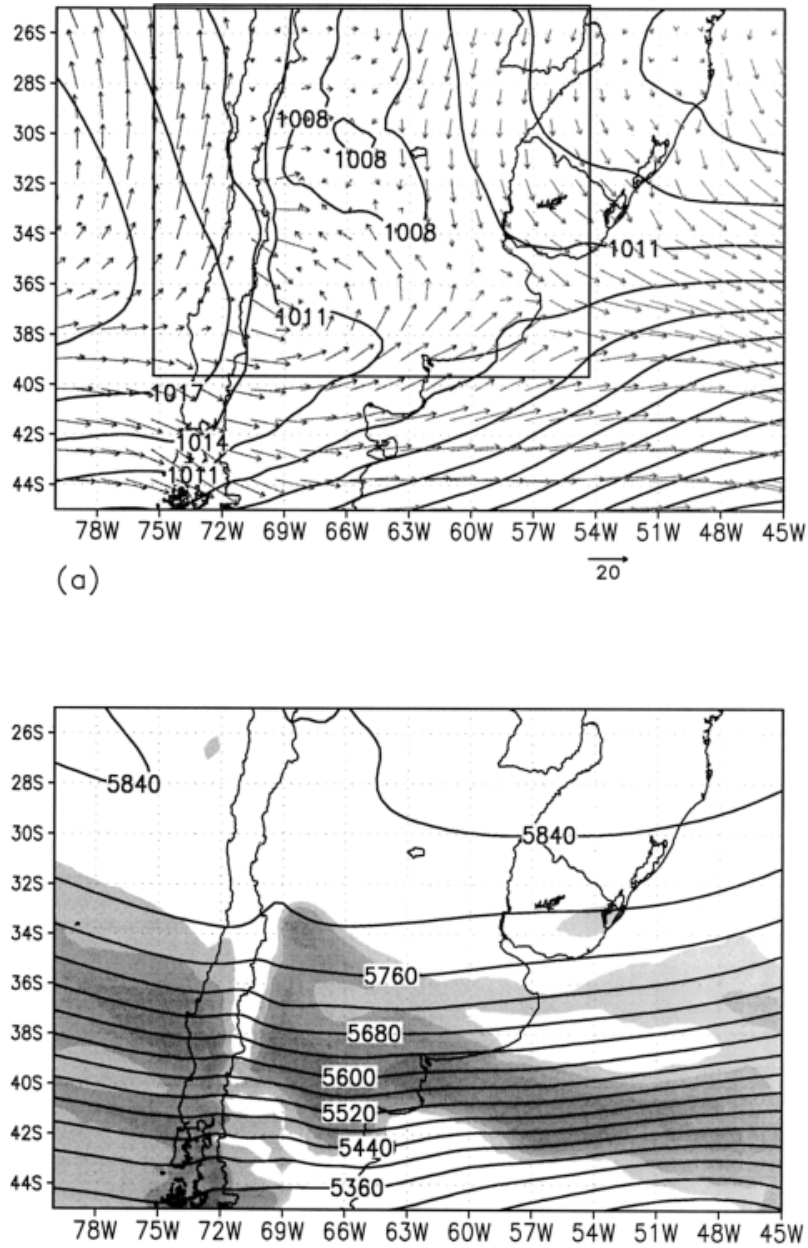

(b)

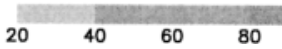

FIG. 15. Same as in Figs. 14a and 14b except for 1800 UTC 10 Aug 1999.

the model previously detected by Seluchi and Chou (2000). The model succeeded in distinguishing the drier humidity profile in Quintero on 10 August compared to the other two cases (figures not included). The forecasted conditions upstream have wind speeds that are greater than observed, which would impact the strength of the mountain wave response generated by the model. This overprediction could compensate for underproduction problems related to the eta coordinate noted by Gallus (2000). The underproduction of moisture would also have an impact on the mountain wave characteristics, which could once again lead to a stronger mountain wave response. However, an extra experiment in which the impact of the latent heat release was removed (figures not included) showed that this isolated effect accounted only for the 5\% of the wind speed on the leeside. This fact is possibly related to the low precipitable water available over the Pacific Ocean near the South American coast.
For a local-scale model evaluation the observed and forecast temperature, dewpoint temperature or humidity, and wind variations at some stations located over the plains as well as at the mountain slopes are compared for the three selected situations.

On 5 August, the zonda wind over Mendoza was indicated by the Eta-CPTEC model with a sharp decrease in moisture, air warming (Fig. 5a), and strengthening of the southwesterly and westerly winds (Fig. 5b). These agree with the observations as the station data and forecast curves (and wind barbs) closely follow each other. The event ended during the nighttime hours, when a steep fall in temperature and an increase in dewpoint temperature were observed. Although the model had some difficulties forecasting the small-scale variations in temperature and humidity prior to zonda, the intensity and starting and ending times of this event were predicted satisfactorily.

Figures $5 \mathrm{c}$ and $5 \mathrm{~d}$ show that the low relative humidity at Aguaditas on the later half of 4 August and in the early hours of 5 August was reasonably forecast. The model variations were smaller and had a delay of approximately $3 \mathrm{~h}$. The wind direction at Aguaditas was also predicted, but forecasted winds were, for the most part, stronger than the observed before, during, and after the zonda event. The zonda at Malargüe was captured by the model (Figs. 5e and 5f).

The high zonda of 10 August was of short duration over the Aguaditas and Potrerillos stations, where it caused a warming of $10^{\circ} \mathrm{C}$ and a moderate drying between 0600 and 1800 UTC on 10 August. Figures 10c and $10 \mathrm{~d}$ show the temporal evolution of the observed and forecast variables at Potrerillos. In this case, the Eta model produced a longer and weaker event. At Mendoza (Figs. 10a and 10b), the zonda signature was not present in either the observations or the model outputs since dewpoint temperature variations were small and winds were weaker than $10 \mathrm{kt}$. Over Malargüe, the model succeeded in reproducing the temperature and moisture. Forecasted winds appear to be slightly weaker than observed.

The performance of the model in the third case (30 August) is evaluated in Fig. 13. The agreement between the forecast and the observed evolutions of the zonda characteristics is remarkable except for the exact intensity and timing of the maximum wind at San Rafael, detected between 1800 and 2100 UTC, which is delayed about $3 \mathrm{~h}$ in the model simulations.

The forecast errors are considered acceptable as the model was able to detect the event and most of its characteristics. Numerical forecasts are limited by the simplifications and the computational load. The current model has $40-\mathrm{km}$ horizontal resolution and 38 layers. The eta layers are thicker at higher altitudes, which can cause errors to the surface-layer schemes. On the other hand, the eta coordinate reduces the pressure gradient force errors near steep mountains such as the Andes. The orography at $40-\mathrm{km}$ resolution cannot represent all 


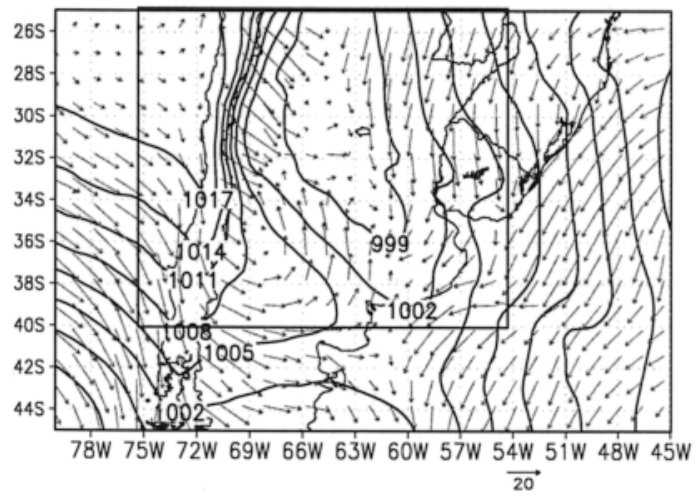

(a)

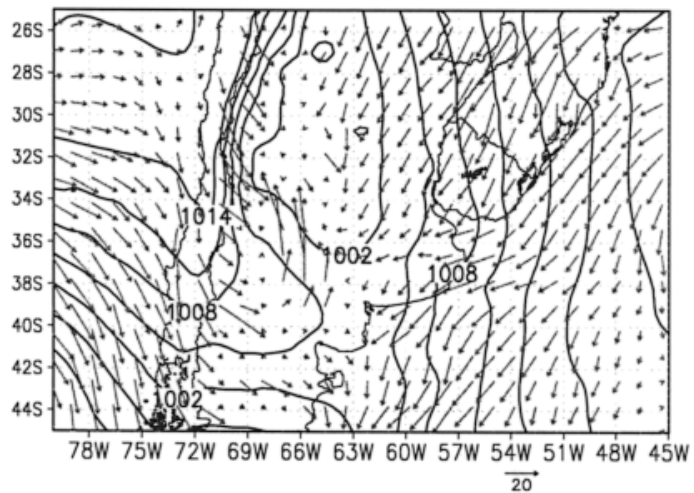

(c)

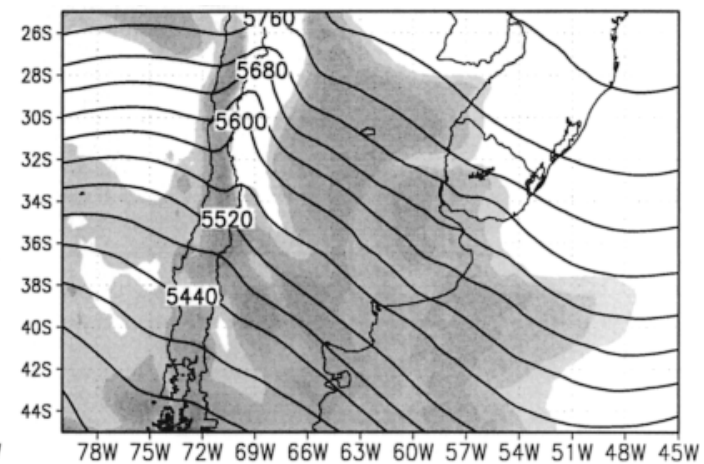

(b)

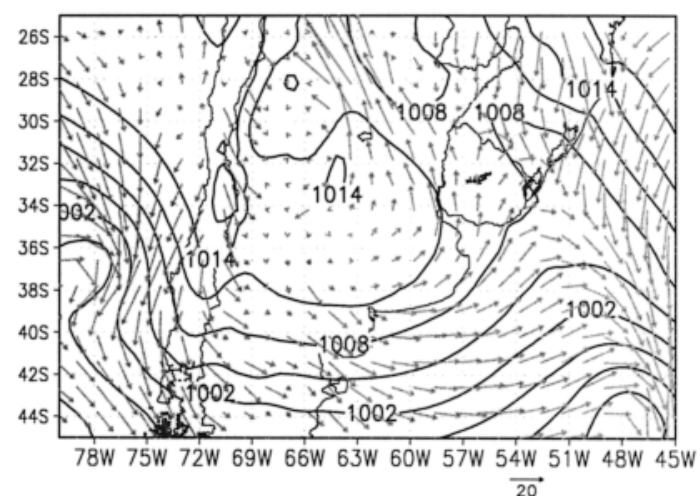

(d)

FIG. 16. Same as in Fig. 14 except for 30 Aug 1999.

of the smaller-scale valleys and hills through which the air can flow; therefore, small-scale variations in temperature, humidity, and winds are not expected to be exactly forecast. Nevertheless, the only increase in horizontal resolution does not assure improved results. Gallus (2000) performed simulations of a downslope windstorm along the Front Range of the Rocky Mountains with an eta coordinate model and found that finer resolution of orography may worsen low-level wind forecasts in the immediate lee of mountains. This may be related to the impact of horizontal resolution on the physical parameterizations.

The initial conditions for the model are provided by the NCEP global analysis, at about $200-\mathrm{km}$ resolution, which contains no mesoscale features. Another factor that can influence the accuracy of the forecast is the quality of the lateral boundary conditions, which are provided at 6-h intervals by the CPTEC-COLA model at spectral triangular truncation T062. For an assessment of the errors due to boundary conditions, the three cases have been simulated using NCEP analyses as the lateral boundary conditions in place of the CPTEC-COLA model forecasts. Figure 17 shows the geopotential and temperature anomaly correlations obtained from analyzed and forecast fields averaged over the whole integration domain and for the three selected cases at the 500- and 1000-hPa levels. These graphs show that the simulations (i.e., specified by NCEP analyses) improve over forecasts by approximately $5 \%$ in terms of anomaly correlation during the later half of the simulation period. Therefore, in the cases studied, using CPTEC-COLA forecasts as lateral boundary conditions resulted in good quality synoptic-scale forecasts.

\section{Physical mechanisms}

This section investigates some physical mechanisms related to the zonda wind and presumably responsible for the differences between the three selected situations. The analysis is based on the Eta-CPTEC model integrations using analyzed lateral boundary conditions.

Due to the scarcity of observation stations and the low resolution of the NCEP reanalysis, the use of the Eta-CPTEC simulations is an alternative solution for a diagnostic study. The horizontal and vertical resolutions of the model allow for a more detailed analysis of some 

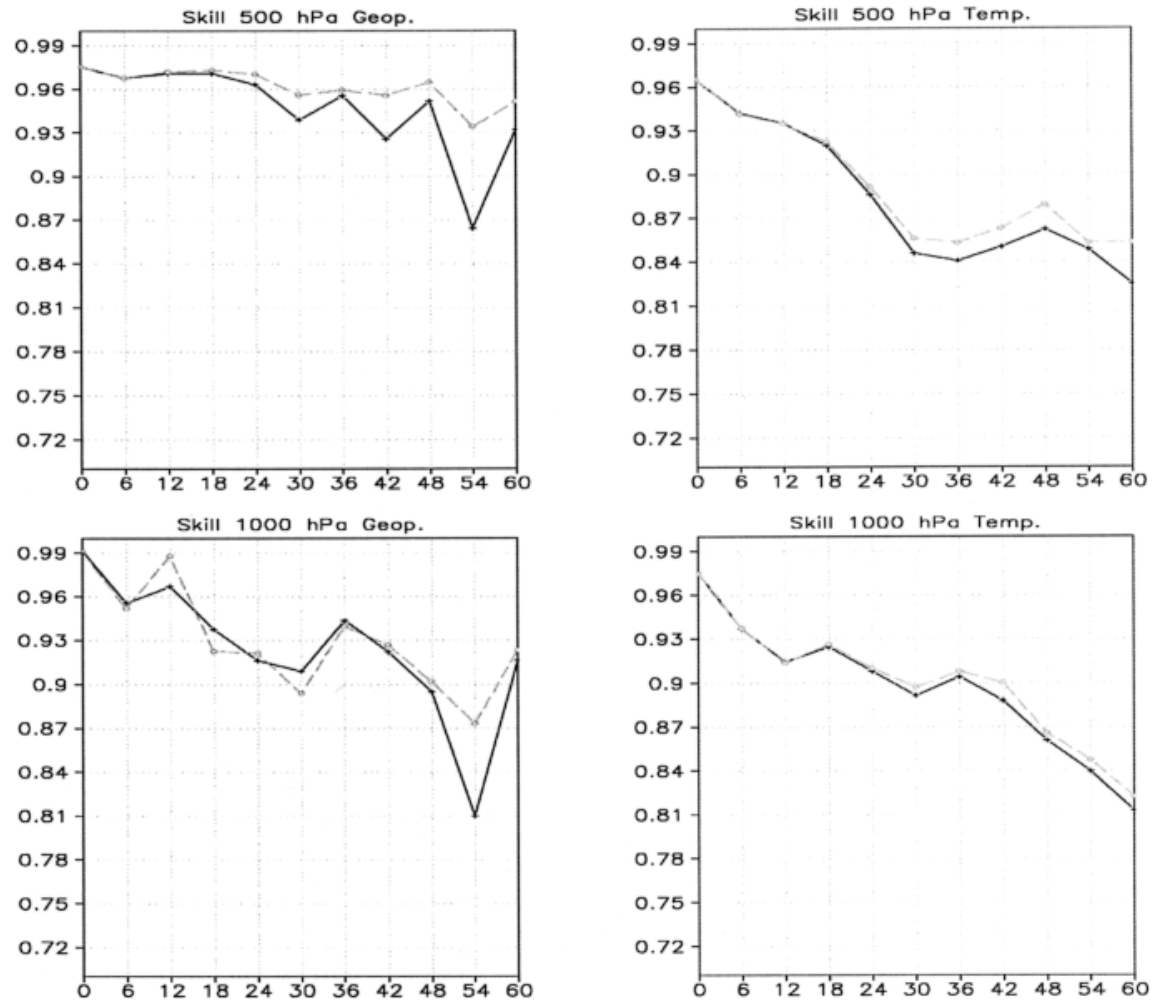

FIG. 17. Mean anomaly correlation between model outputs, forecasts, and simulations, obtained by the Eta-CPTEC model and NCEP analysis for (left) geopotential height and (right) temperature at the (above) 500- and (below) 1000-hPa levels. The solid lines correspond to the score averaged over the three situations for 42 -h forecasts (i.e., initiated $42 \mathrm{~h}$ before the appearance of the zonda wind). The dashed lines correspond to the simulations (analyzed boundary conditions) obtained for the same period. Time on the $x$ axis represents hours of integration.

aspects of these small temporal- and spatial-scale events. Because of the acceptable agreement shown in the previous section between the observed characteristics and those simulated by the Eta-CPTEC model, this model can be used as a tool for studying the physical processes leading to the zonda appearance.

The vertical cross sections of the potential temperature corresponding to 1200 UTC on 4 August, 1800 UTC on 5 August, and 1200 UTC on 6 August along $33^{\circ} \mathrm{S}$ are shown in Fig. 18. Prior to the zonda eruption (Fig. 18a) there was a contrast in the stability between the air of the two sides of the Andes. A stable layer is detected on the windward side between 950 and 700 $\mathrm{hPa}$, while on the lee side the air is less stable. The inversion close to the surface east of $64^{\circ} \mathrm{W}$ is due to nocturnal cooling. East of the Andes, the slope of the isentropes and the subsidence above the $700 \mathrm{hPa}$ suggest a foehn effect (high zonda). During the zonda eruption over the plains (Fig. 18b), the stability conditions diminish in the lower levels on the lee side of the mountain above $900 \mathrm{hPa}$ and the vertical movements become intense. Near the mountaintop, at about $700 \mathrm{hPa}$, there is a thin stable layer on the windward side. This feature was also observed by Seibert (1990) during foehn events. The ascent on the windward side caused cloudy weather conditions over the western slopes and at the summit, in accordance with the hand analysis. Air descends abruptly on the lee side and reaches the surface. The quasi-vertical slope of the isentropes suggests that the air goes down adiabatically. The zonda was disrupted at midnight of 5 August by the cold front passage. The frontal inversion can be seen on the lee side above $800 \mathrm{hPa}$ in Fig. 18c. Nevertheless, high zonda signals persisted above $700 \mathrm{hPa}$.

During the 10 August event, although no evidence of surface zonda was simulated (Fig. 19), a high zonda situation was indicated by the magnitude of the downward vertical velocity on the mountaintop and the subsidence inversion on the lee side. The case of 30 August had characteristics similar to those shown in Fig. 18, except for the vertical velocity, which was less intense, and the leeside isentropes showed a smaller slope.

Figure 20 shows the temporal evolution of the equivalent potential temperature $\left(\theta_{e}\right)$ difference between the 500- and 1000-hPa levels and the magnitude of the vertical velocity at the 700-hPa level simulated at model grid points near Quintero and Mendoza, for the 5 August case. On the windward side, the rising motion in the lower troposphere starts around 1200 UTC on 4 August, and reaches maximum speed around 0000 UTC on 5 

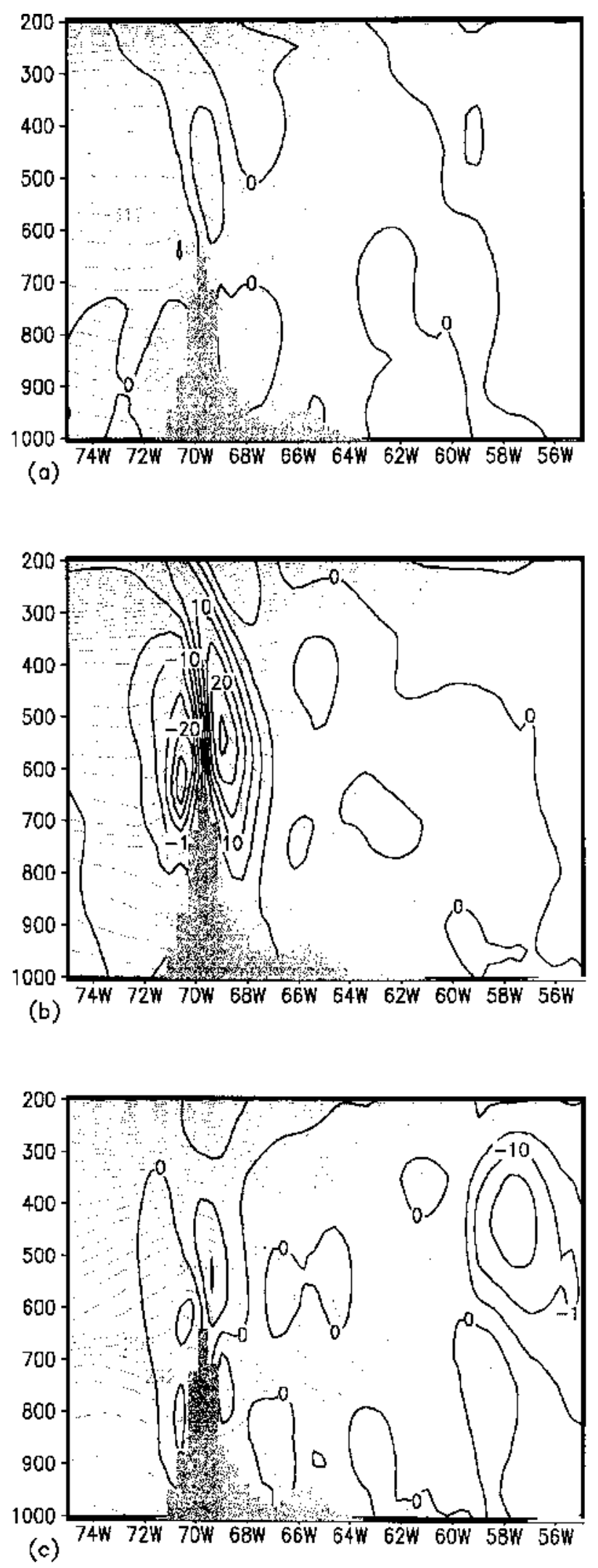

FIG. 18. Vertical cross sections of the equivalent potential temperature ( $\mathrm{K}$, dashed lines), vertical velocity $\left(\mathrm{hPa} \mathrm{s}^{-1}\right.$, solid lines) at
August (Fig. 20a). The decrease of the windward stability follows later in the early hours of 5 August leading to instability conditions in the late hours on 5 August. Descent of air on the lee side starts after 1200 UTC on 4 August (Fig. 20b), a few hours before the zonda wind is detected at Potrerillos, but reaches its full strength the next day at 1200 UTC. The stability conditions diminish gradually and the lower troposphere becomes an adiabatic layer on 6 August.

Under normal conditions, the South Pacific subtropical anticyclone west of the central Andes generates an intense and persistent subsidence inversion (Rutllant 1994) that separates a shallow layer of marine air from an upper dry air mass. There is some evidence in Fig. 20 (notice the $\theta_{e}$ difference reaching zero at 0000 UTC) that air parcels located initially near or even under the thermal inversion have been raised to the mountaintop level ahead of the cold front and latter crossed the Andes Cordillera, participating in the zonda eruption. Trajectory analysis (figure not shown) confirms that humid air initially placed under the thermal inversion was able to cross the mountain barrier causing bad weather on the western slopes and on the mountaintop.

In the case of the high zonda of 10 August only a moderate decrease of the inversion intensity was noticed, perhaps because of the less intense vertical movements, whereas in the severe zonda the thermal inversion disappeared. The reduction of the stability and the subsidence was also smaller over the eastern slope than in the previous case.

The situation occurring on 30 and 31 August exhibited a behavior similar to that shown in Figure 20, including the existence of a light thermodynamic instability around 1800 UTC on 30 August. However, the reduction in the vertical gradient of $\theta_{e}$ and the magnitude of the vertical velocity were smaller.

The previous analysis shows that, in the chosen cases, the intensity and height of the windward thermal inversion are presumably related to the presence and intensity of the zonda wind. This offers some guidance for the operational forecasters of the region, since this inversion is controlled by larger-scale mechanisms (i.e., rising motion produced by a midlevel trough, and frontal activity).

Additional information can be obtained by considering the Froude number $(\mathrm{Fr})$, linked to the flow over orographic obstacles. This can be calculated as

$$
\mathrm{Fr}=\frac{U}{N H},
$$

where $U$ is the velocity of the wind perpendicular to the obstacle, $H$ is the height of the mountain "seen" by

$\leftarrow$

$33^{\circ} \mathrm{S}$ from simulations at (a) 1200 UTC 4 Aug (12-h integration), (b) 1800 UTC Aug 5 (42-h integration), and (c) 1200 UTC 6 Aug (60$\mathrm{h}$ integration), 1999. 


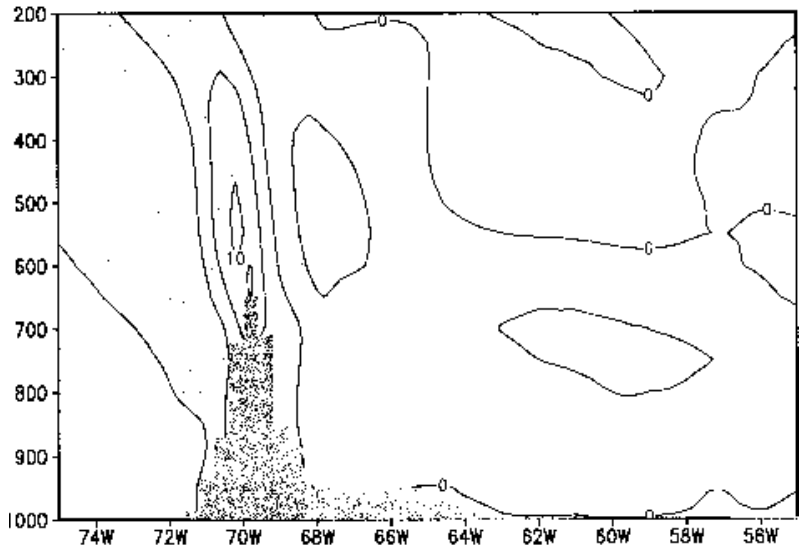

FIG. 19. Same as in Fig. 18 except for 1200 UTC 10 Aug (36-h integration).

each pressure level (distance between the level and the top of terrain), and $N$ is the Brunt-Väisälä frequency.

The square of the Froude number is proportional to the ratio between the kinetic energy and the potential energy of the flow. Consequently, a low Fr characterizes a situation of "orographic blocking," while a high Fr $(\geq 1)$ implies that the flow has enough energy to traverse the mountain barrier (Bluestein 1993).

Figure 21 describes the temporal evolution of Fr over the west coast of South America $\left(34^{\circ} \mathrm{S}, 75^{\circ} \mathrm{W}\right)$ at the 850-, 700-, and 500-hPa levels for the three chosen events. In order to avoid high Fr numbers at the 500$\mathrm{hPa}$ level, the real Andean topography was considered, including mountain peaks of $6000 \mathrm{~m}$. Meteorological variables were extracted from model outputs, and vertical derivatives were obtained through finite differentials between the levels immediately above and below the particular pressure level. The maximum Fr values attained in the 5 August case (Fig. 21a) were higher than in the other two events (Figs. 21b and 21c), showing a greater flow predisposition to overcome the mountains. In this situation, Fr values indicate the possibility of traversing the Andes at all three levels, 850, 700, and $500 \mathrm{hPa}$, during the afternoon of 5 August. In the second episode, which is a high zonda event, the numbers are $\geq 1$ only above $700 \mathrm{hPa}$ (Fig. 21b). During the event of 29-31 August, the possibility of a high zonda is evident throughout the simulation. The occurrence of the phenomenon at the $850-\mathrm{hPa}$ level for a short duration appears around 1800 UTC of 30 August, the moment it was effectively detected.

The zonda wind situations are marked by the appearance of an intense zonal pressure gradient on the lee side. Figure 22 shows the magnitude of the simulated pressure gradient force at mean sea level for the three cases: before, during, and after the appearance of the zonda wind. A pressure gradient force maximum was observed over and on the lee side of the Andes. However, its strengthening from before the zonda eruption to the eruption period and subsequent weakening and
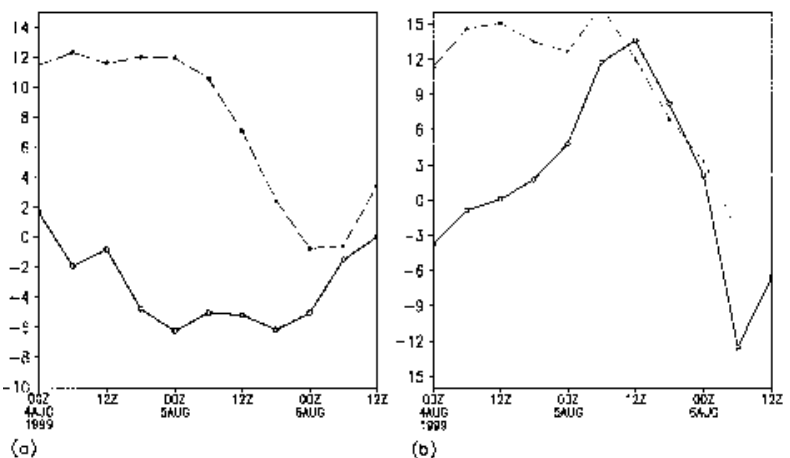

FIG. 20. Difference of the equivalent potential temperature (K) between the 500- and 1000-hPa levels (dashed lines) and magnitude of the vertical velocity (solid lines) $\left(\mathrm{hPa} \mathrm{s}^{-1}\right)$ at (a) $34^{\circ} \mathrm{S}, 75^{\circ} \mathrm{W}$ and (b) $34^{\circ} \mathrm{S}, 68^{\circ} \mathrm{W}$ simulated by the Eta-CPTEC model.

its movement to north are worth noting. In the analyzed cases the magnitude of the gradient pressure force is related to the zonda wind intensity. This is in agreement with previous results obtained by Norte (1988) who identified the pressure difference between San Juan and La Serena (on the windward side of the Andes) as a good zonda predictor. Furthermore, the latitudinal extension of the maximum gradient pressure force seems to show some connection to the area impacted by the foehn effect.

\section{Discussion and concluding remarks}

Three zonda cases are analyzed in some detail in this work. The first one, which occurred on 5 August 1999, was a severe surface episode, while the case of $10 \mathrm{Au}-$ gust was an example of a typical high zonda. The situation of 30 August was considered to be a moderate surface zonda case. The three episodes were forecasted with acceptable accuracy by the Eta-CPTEC model, with approximately 48-h lead time.

The foehn effect is not evident in the NCEP reanalyses, because of its relatively low spatial and temporal resolution and the sparse observation network of the region. This fact stimulates the use of high-resolution regional models to study the phenomenon. Because of the satisfactory agreement between the observations and forecasts, the Eta-CPTEC model output was used to perform a regional/mesoscale description and to analyze the role of topography and the influence of some physical mechanisms on the zonda characteristics.

The three zonda cases were satisfactory diagnosed by the Froude numbers (Fr) obtained upstream of the orographic obstacle. High Froude numbers in the middle and higher troposphere are characteristic of the middlelatitude circulation; this fact is also verified each time the jet stream traverses the Andes. In the high zonda (10 August) case, the zonal pressure gradient at the surface was weaker and the jet stream was stronger and more zonal than in the surface zonda case (5 August) over the Mendoza latitude. Strong flow above the moun- 

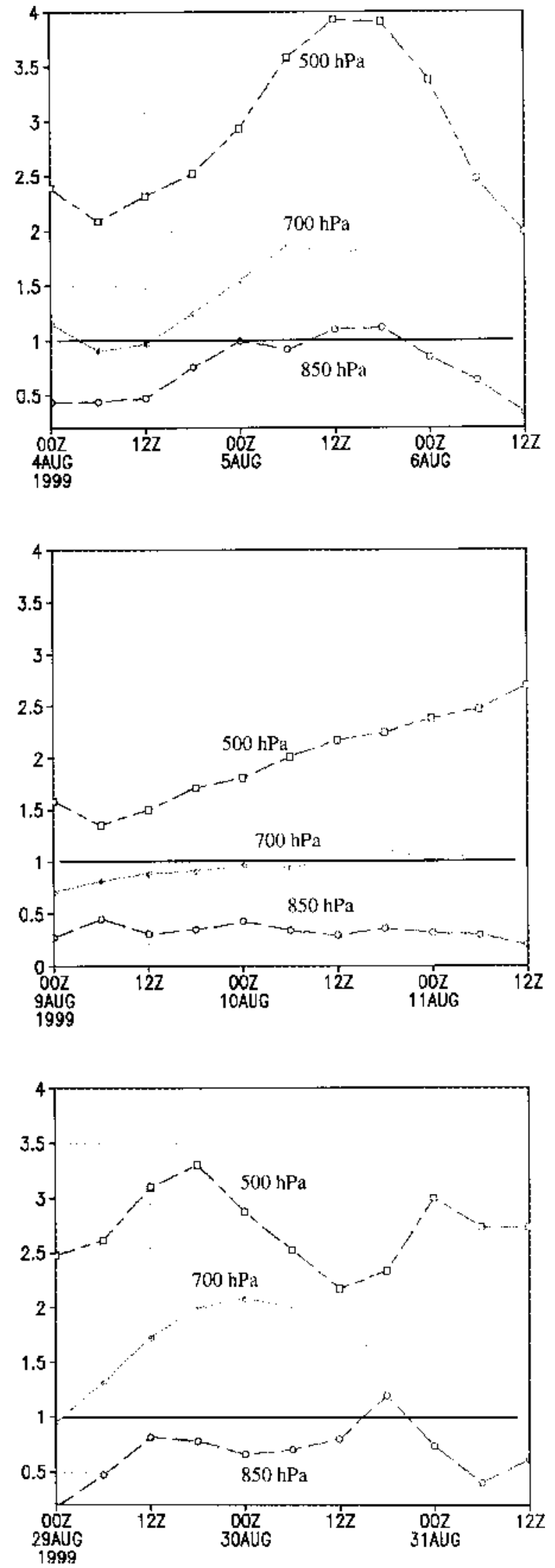

taintop is usually taken as an inhibiting factor of the low-level mountain wave amplification by suppressing wave breaking aloft.

The strength of the pressure gradient force across the Andes seems to have some connection with the zonda eruption, in agreement with the current statistical forecast methods. On the other hand, the latitudinal extent of the area affected by the zonda could be related to the location of the maximum pressure gradient force. This across-mountain pressure gradient is the result of a mountain wave superimposed to the regional baric pattern.

The synoptic configuration associated with the eruption of the zonda wind was characterized by the displacement of frontal systems in connection to depressions that moved toward lower than normal latitudes. According to various authors (Taljaard 1967; Necco 1982; Sinclair 1995), in these regions the cyclones normally travel south of $55^{\circ} \mathrm{S}$, while in the chosen situations they moved near $45^{\circ} \mathrm{S}$. In the case of 5 August, the mountain wave was related to a depression that crossed the Andes near $50^{\circ} \mathrm{S}$ associated with the proximity of an upper-level trough. The zonal pressure gradient maximum occurred when the front was immediately south of Mendoza, at 1800 UTC, that is, when the zonda was blowing near the surface over the city. According to Norte (1988), this is the most frequent configuration observed in the severe cases of the zonda wind affecting the plain. However, in the events of 10 and 30 August no strong frontal configuration was observed.

One of the difficulties usually encountered by the surface humid air mass located over the Pacific Ocean to traverse the Andean barrier is the presence of the subsidence inversion. During zonda episodes, instability conditions and rising motion were verified on the windward side of the Andes. However, near the mountaintop a more stable layer is observed on the windward side. The magnitude and timescale of the upward motion and its duration (see Fig. 18) are linked to synoptic-scale systems. This behavior is associated with the existence of a trough at the middle levels of the atmosphere.

In the 30 August case, a surface zonda wind occurred close to the hour of maximum temperature, in agreement with the climatic characteristics found by Norte (1988). The event of 5 August began near midday, which coincided with the climatological timing for the severe episodes features (Norte 1988). It is likely that vertical mixing induced by the diurnal heating in the cloud-free region on the lee side is a mechanism that helps break or weaken the subsidence inversion in that region and, consequently, favors the eruption of the wind over the surface.

FIG. 21. Temporal evolution of Fr, obtained from the diagnostics of the Eta-CPTEC model at $34^{\circ} \mathrm{S}, 75^{\circ} \mathrm{W}$ at 850,700 , and $500 \mathrm{hPa}$ for the situations of (a) 5, (b) 10, and (c) 30 Aug 1999. 

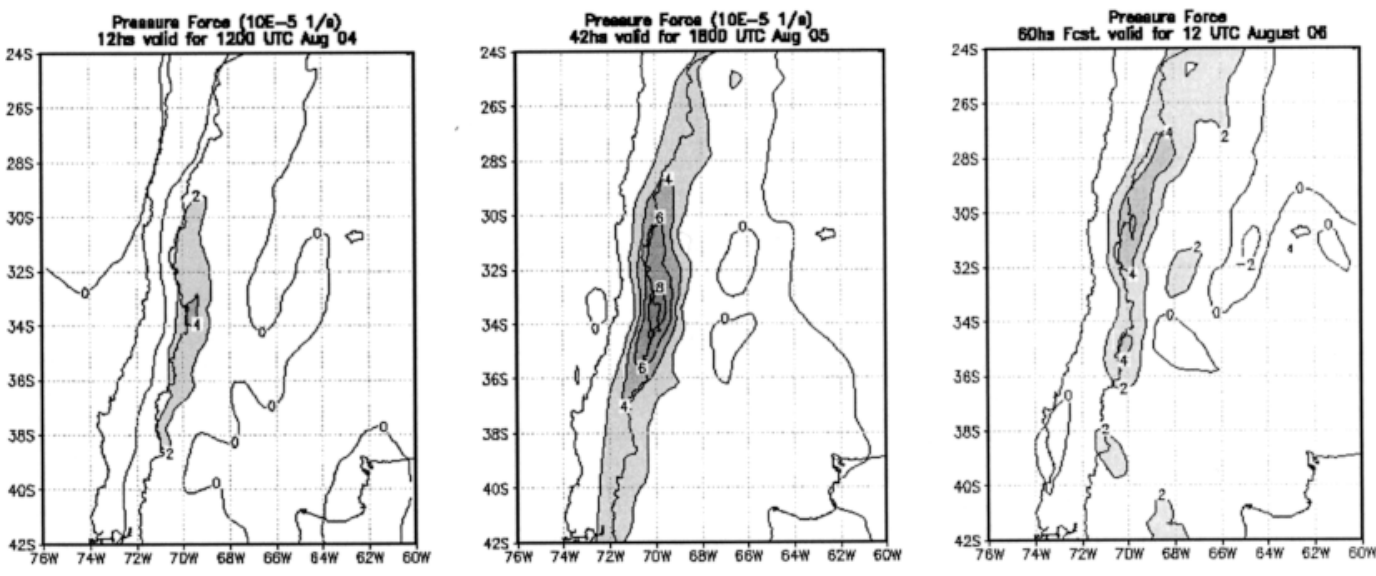

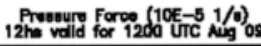
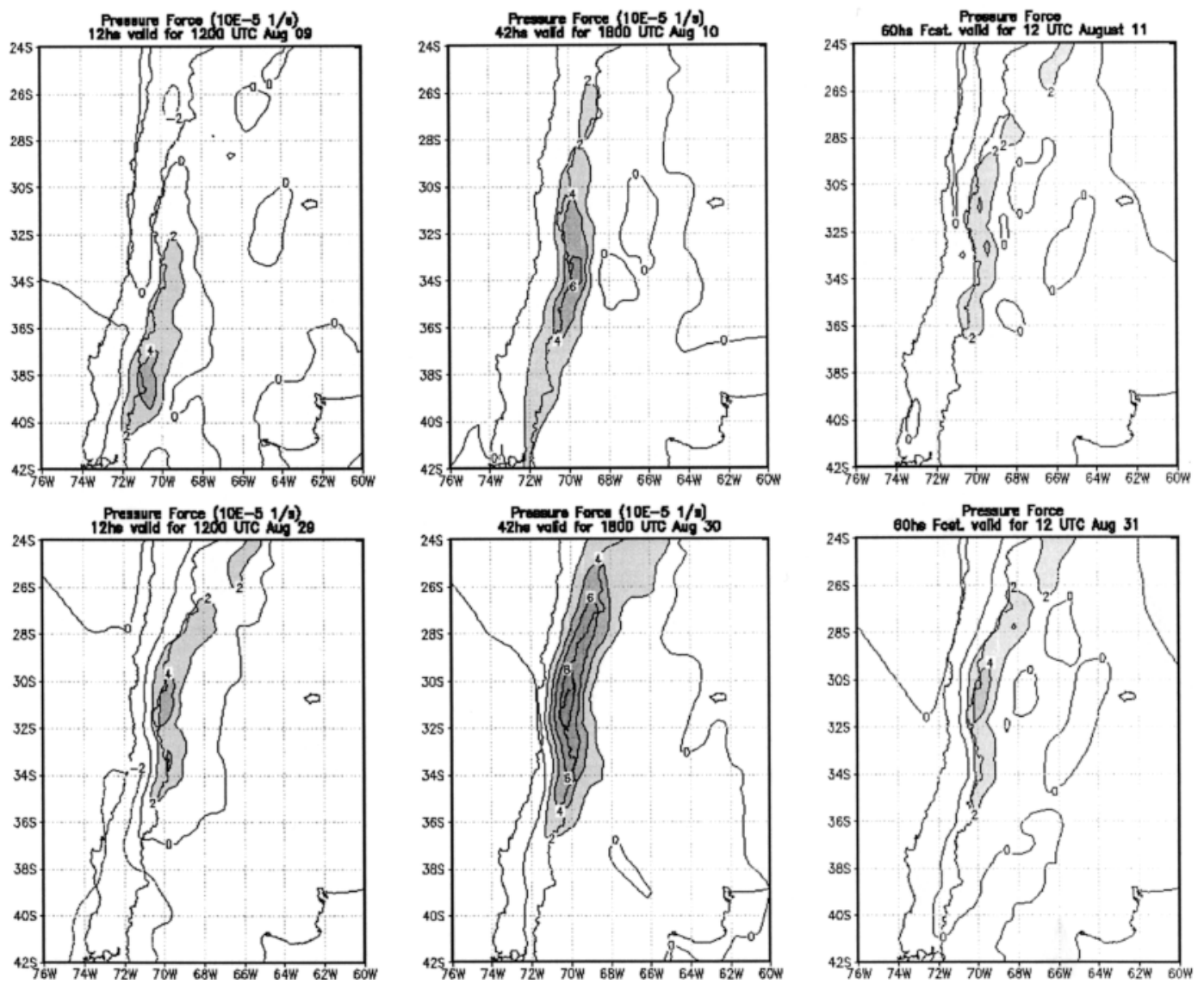

FIG. 22. Magnitude of the pressure gradient force $\left(10^{-5} \mathrm{~m} \mathrm{~s}^{-2}\right)$ at the lowest model level obtained from the model simulations for the indicated days and hours. Values higher than $210^{-5} \mathrm{~m} \mathrm{~s}^{-2}$ are shaded.

In order to determine the role of the height of the topographic obstacle, two experiments were conducted where the height of the Andes was reduced by $25 \%$. As the initial conditions were not modified to perform these integrations, the flow may still contain the "normal" orography signal and therefore the desired effect may be slightly reduced. Figure 23 shows, for two zonda cases, the difference of wind speed near the surface between the two experiments, with reduced and normal
Andes height. Clear differences are noticed in both cases. When the height of the topography is reduced, the resulting winds are comparatively weaker in the severe zonda event (Fig. 23a), indicating a less intense foehn effect. A vertical cross section constructed along $34^{\circ} \mathrm{S}$ (not included) shows less tilted isentropes with a shorter vertical trajectory and vertical movements of lower magnitude in the experiment with reduced topography. In other words, a smaller obstacle seems to lead to a 


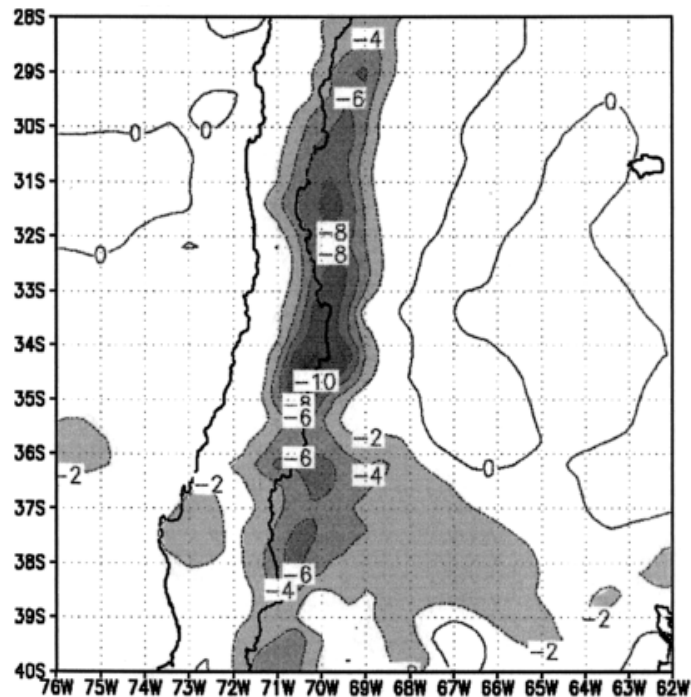

(a)

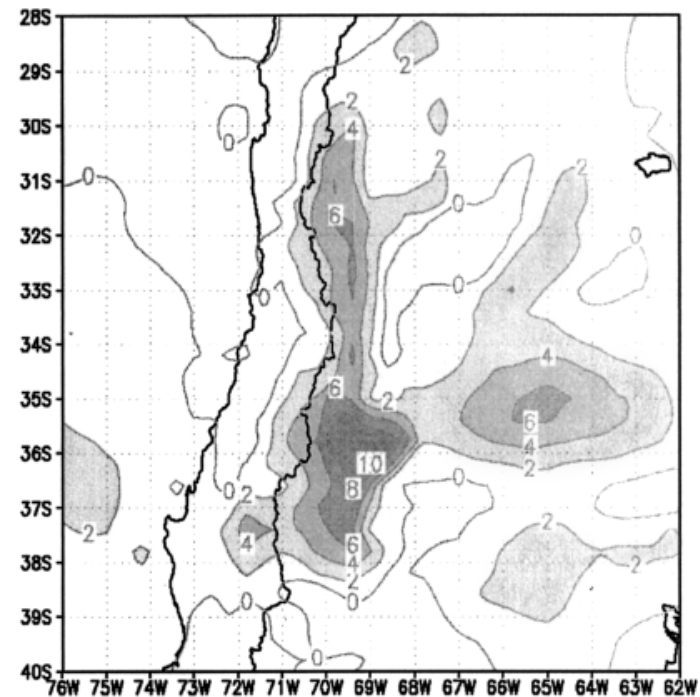

(b)

FIG. 23. Difference in the 925-hPa wind magnitude between the control experiment and the one in which the Andes height was multiplied by a factor of 0.75 . (a) After $42 \mathrm{~h}$ of integration, valid for 1800 UTC 5 Aug (values lower than $-2 \mathrm{~m} \mathrm{~s}^{-1}$ are shaded). (b) After $42 \mathrm{~h}$ of integration, valid for $1800 \mathrm{UTC}$ of 10 Aug. Values higher than $1 \mathrm{~m} \mathrm{~s}{ }^{-1}$ are shaded.

less intense drying and warming process. The reduced intensity may be a manifestation of the amplitude of a mountain wave being proportionate to mountain height. In the case of a high zonda, the resulting westerly winds are stronger in the experiment with reduced orography (Fig. 23b). It can be deduced from these experiments that a hypothetically lower height of the Andes would probably lead to more frequent but less intense zonda wind episodes. The presence of winds of orographic origin at the surface close to Malargüe during 10 August (where the Andes are lower), but only blowing high in Mendoza, helps to support the hypothesis.

Notwithstanding the small number of cases analyzed, the satisfactory performance of the Eta-CPTEC model offers encouragment for its use for forecasting purposes. This would represent a significant scientific advance, as until the present the forecasting of these episodes was only performed using statistical tools based on probabilities of occurrence. Integration of the model over the studied region with an adequate horizontal and vertical resolution by numerically nesting the Eta-CPTEC model in itself would provide useful forecast guidance on the descending winds and the consequent temperature and humidity variations over the mountain and the adjoining plains. This fact has important social impacts over western Argentina, because on many occasions the zonda wind caused significant material damage and even the loss of human lives.

Acknowledgments. The authors wish to thank Silvia Simonelli and Julio Cristaldo for their essential collaboration and to María Elena Soler for translating the manuscript into English. The first author undertook this re- search through a visiting scientist grant from the Brazilian Conselho Nacional de Desenvolvimento Científico e Tecnológico (CNPq). The work was partially financed by the Fundacão de Amparo à Pesquisa do Estado de São Paulo (FAPESP), Brazil.

\section{REFERENCES}

Betts, A. K., and M. J. Miller, 1986: A new convective adjustment scheme. Part II: Single column test using GATE wave, BOMEX, and arctic air-masses data sets. Quart. J. Roy. Meteor. Soc., 112, 1306-1335.

Black, T. L., 1994: The new NMC mesoscale Eta Model: Description and forecast examples. Wea. Forecasting, 9, 256-278.

Bluestein, H. B., 1993: Synoptic-dynamic Meteorology in Midlatitudes, Vol. II, Observations and Theory of Weather Systems. Oxford University Press, $953 \mathrm{pp}$.

Brinkmann, W. A. R., 1971: What is foehn? Weather, 26, 230-239.

- 1974: Strong downslope winds at Boulder, Colorado. Mon. Wea. Rev., 102, 592-602.

Chen, F., and R. Avissar, 1994: The impact of land-surface wetness on mesoscale heat fluxes. J. Appl. Meteor., 33, 1324-1340.

Durran, D., 1986: Another look at downslope windstorms. Part I: The development of analogs to supercritical flow in an infinitely deep, continuously stratified flow. J. Atmos. Phys., 43, 2527-2543.

_ 1990: Mountain waves and downslope winds. Atmospheric Processes over Complex Terrain, Meteor. Monogr., No. 45, Amer. Meteor. Soc., 59-81.

Egger, J., and K. P. Hoinka, 1992: Fronts and orography. Meteor. Atmos. Phys., 48, 3-36.

Fleagle, E., 1950: A theory of air drainage. J. Meteor., 7, 227-232.

Gallus, W. A., Jr., 2000: The impact of step orography on flow in the Eta Model: Two contrasting examples. Wea. Forecasting, 15, 630-637.

Garreaud, R., 1999: Multiscale analysis of the summertime precipitation over the central Andes. Mon. Wea. Rev., 127, 901-921.

Janjić, Z. I., 1994: The step-mountain eta coordinate model: Further 
developments of the convection viscous sublayer and turbulence closure schemes. Mon. Wea. Rev., 122, 927-945.

Kalnay, E., and Coauthors, 1996: The NCEP/NCAR 40-Year Reanalyses Project. Bull. Amer. Meteor. Soc., 77, 437-471.

Klemp, J. B., and D. K. Lilly, 1975: The dynamics of wave induced downslope winds. J. Atmos. Sci., 32, 78-107.

Lamb, P., 1974: Northwesters potential foehn influence on Canterbury plains (New Zealand) surface heat exchanges. N. Z. J. Agric. Res., 17, 349-355.

Lilly, D. K., 1978: A severe downslope windstorm and aircraft turbulence event induced by a mountain wave. J. Atmos. Sci., 35, $59-77$.

Lindesay, J. A., 1990: Thermo-topographically boundary-layer oscillations over the central Namibia, southern Africa. Int. J. Climatol., 10, 63-77.

Maninns, P. C., and B. L. Sawford, 1979: A model of katabatic wind. J. Atmos. Res., 36, 619-630.

Mesinger, F., 1984: A blocking technique for representation of mountains in atmospheric models. Riv. Meteor. Aeronaut., 44, 195202.

Necco, G. V., 1982: Comportamiento de vórtices ciclónicos en el área sudamericana durante el FGGE: trayectorias y desarrollos. Meteorologica, 3, 21-34.

Norte, F. A., 1988: Características del viento Zonda en la Región de Cuyo. Ph.D. thesis, [Available from Programa Regional del Meteorología, CRICYT, Mendoza, Argentina, and Departamento de Ciencias de la Atmosfera, Ciudad Universitaria (1428), Buenos
—_, and M. E. Seluchi, 1993: Objective methods for the zonda forecasting using information from surface and height. Preprints, Fourth Int. Conf., on the Southern Hemisphere Meteorology and Oceanography, Hobart, Australia, Amer. Meteor. Soc., 258-259.

— wind in Argentina. Preprints, 14th Conf. on Weather Analysis and Forecasting, Dallas, TX, Amer. Meteor. Soc., 128-129.

— J. Cristaldo, and M. Silva, 1996: El viento Zonda identificado con imágenes satelitales. Proceedings CONGREMET VIII, 273 274.

Oard, M. J., 1993: A method for predicting chinook winds east of the Montana Rockies. Wea. Forecasting, 8, 166-180.

Rutllant, J., 1994: On the generation of coastal lows in central Chile Int. Centre for Theoretical Physics Internal Rep. IC/94/67, Trieste, Italy, ?? pp.

Seibert, P., 1990: South foehn studies since the Alpex experiment Meteor. Atmos. Phys., 43, 91-103.

Seluchi, M. E., and S. C. Chou, 2000: Diagnosing systematic errors in the Eta model Forecasts over South America. Preprints, Sixth Int. Conf. on Southern Hemisphere Meteorology and Oceanography, Santiago, Chile, Amer. Meteor. Soc., 422-423.

Sinclair, M. R., 1995: A climatology of cyclogenesis for the Southern Hemisphere. Mon. Wea. Rev., 123, 1601-1619.

Taljaard, J. J., 1967: Development, distribution and movement of cyclones and anticyclones in the Southern Hemisphere during I.G.Y. J. Appl. Meteor., 6, 973-987.

Wakonigg, H., 1990: The north foehn in the south-eastern Alpine border zone. Mitt. Oesterr. Geol. Ges., 132, 27-55.

Zydek, F., 2000: Chinook wind. South Dakota Rev., 38 (1), 54-54. 